\title{
Microbiome-Gut-Brain-Axis Communication Influences Metabolic Switch in the Mosquito Anopheles Culicifacies
}

RAJNIKANT DIXIT ( $\sim$ dixit2k@yahoo.com )

National Institute of Malaria Research https://orcid.org/0000-0002-3536-8329

\section{Research Article}

Keywords: Mosquito, blood-feeding, metabolic switch, gut-brain-axis communication, microbiome

Posted Date: September 7th, 2021

DOI: https://doi.org/10.21203/rs.3.rs-250534/v2

License: (c) (i) This work is licensed under a Creative Commons Attribution 4.0 International License.

Read Full License 


\section{Abstract}

Periodic ingestion of a protein-rich blood meal by adult female mosquitoes causes a drastic metabolic change in their innate physiological status, which is referred to as 'metabolic switch. Although the downregulation of olfactory factors is key to restrain host-attraction, how the gut 'metabolic switch' modulates brain functions, and resilience physiological homeostasis remains unexplored. Here we demonstrate that the protein-rich diet induces the expression of brain transcripts related to mitochondrial function and energy metabolism, possibly to cause a shift of the brain's engagement to manage organismal homeostasis. A dynamic expression pattern of neuro-signalling and neuro-modulatory genes in both gut and brain, establishes an active brain-distant organ communication. Disruption of this comunication through decapitation, does not affect the modulation of the neuro-modulator receptor genes in the gut. In parallel, an unusual and paramount shift in the level of the Neurotransmitters (NTs), from the brain to the gut after blood feeding, further supports the idea of the gut's ability to serve as a 'second brain'. Finally, a comparative metagenomics evaluation of gut microbiome population dynamics, highlighted that bloodfeeding not only suppresses Enterobacteriaceae family member by $50 \%$, but favors rapid proliferation of Pseudomonadales to $46 \%$ of the total community. Notable obesrvation of a rapid proliferation of Pseudomonas bacterial sp. in the gut correlates a possible cause for the suppression of appetite after blood-feeding. Additionally, an altered NTs dynamics of naïve and aseptic mosquitoes provide the initial evidence that gut-endosymbionts are key modulators for the synthesis of major neuroactive molecules.

Conclusion: Our data establish a new conceptual understanding of microbiome-gut-brain-axis communication in mosquitoes.

Data deposition: Mosquito Brain RNAseq data are accessible under Accession IDs: SRR9853884 (Ac-BrSF); SRR9853885 (Ac-Br-BF-30Min), SRR9853883 (Ac-Br-BF-30hrs) at NCBI repository. Mosquito Gut metagenomics data are accessible under accession IDs: SRR12579422 (Ac-MG-SF); SRR12622557 (AcMG-BF) at NCBI repository.

\section{Highlights}

- Highly proteinaceous blood meal uptake causes gut 'metabolic switch' activity in mosquitoes.

- Gut's calling shifts the brain's administrative function from external communication to inter-organ management.

- 'Gut', as a 'Second brain' plays a crucial role in the maintenance of physiological homeostasis.

- Metabolic switch and proliferation of symbiotic bacteria establish microbiome-gut-brain axis communication in mosquitoes.

\section{Introduction}

The brain is a privileged organ in shaping an animal's behavior from lower to higher taxa by guiding and managing the diverse nature of external and internal stimuli. While each and every behavior of any 
organism is finely orchestrated by multiple organs, it is the brain that directs and exchange decisionmaking actions to regulate distinct organs functions. Unlike human brain, which hosts billions of neurons, it is amazing to know how blood-feeding mosquitoes, having less than 1,00,000 neurons in their tiny brain, regulate diverse functions such as finding a suitable source for sugar feeding and bloodfeeding, searching for a mate-partner, and locating a proper oviposition site for egg-laying, etc. Decades of research highlights that the molecular interaction of olfactory-derived odorant-binding proteins (OBPs), their olfactory receptors (Ors), and environmental chemical cues (external cues) is central to shape these behaviors(Potter 2014; De et al. 2018b). Additionally, the innate physiological status of the mosquitoes such as satiated/starved, mated/unmated, nutritional status, gravid, or not, also account to the successful accomplishement of these behavioral activities (Das De and Dixit 2020). Thus, how the miniature brain of mosquitoes harmonizes internal and external cues and affects decision-making abilities, is yet unknown.

Upon locating a suitable vertebrate host, a positive feeding decision stimulates the salivary glands to facilitate rapid blood meal ingestion by the adult female mosquitoes, and temporarily arrest the olfactory actions until 30h of blood-feeding(De et al. 2018b). Though, a fully engorged female mosquito shows a dramatic suppression of host-seeking behavior until the eggs are laid ( $72 \mathrm{~h}$ post blood meal) however, to accompany complex oviposition site finding behaviors, reactivation of the peripheral sensory system (30-40h post blood meal) is deemed necessary (Takken et al. 2001; Duvall et al. 2019). A recent study by Duvall et. al. indicates that activation of Neuropeptide Y (NPY) signaling is essential in the suppression of host-seeking behavior for several days after blood feeding(Duvall et al. 2019). However, we have limited knowledge on how the mosquito's brain regulates the binary behavioral switch responses (sugar to bloodfeeding), and maintain organismal physiology in blood-fed females.

Fast engorgement of the mosquito's gut with blood causes a drastic metabolic shift in the innate physiological status from sugar to a protein-rich diet, resulting in the alteration of cellular fuel sources. This 'metabolic switch' is expected to drive multiple organs' engagement to perform their respective functions, such as osmoregulation by Malpighian tubules, progressive blood meal digestion by the gut, nutrient mobilization, and activation of vitellogenesis in the fat body, and ovary development for egg maturation(Sanders et al. 2003; Beyenbach 2012; Badisco et al. 2013; Beyenbach and Petzel 2017; Liu and Jin 2017; Duvall 2019). It is the central nervous system that ensures institutes inter-organ communication to manage the rapidly changing inner physiological activities. Several neuromodulators, such as neuropeptides, neurotransmitters, and neurohormones having a role in neuro-synaptic signal transmission and inter-organ communication, have been characterized in fruit fly(Droujinine and Perrimon 2016; Liu and Jin 2017). However, a similar correlation between the gut metabolic switch and brain function modulation in mosquitoes is limited to the Aedes aegypti, where brain secreted Insulin-likepeptide 3 is reported to play a significant role in the regulation of blood meal digestion and egg development (Gulia-Nuss et al. 2011). Only a few recent genetic studies have suggested the key role of few neuropeptides e.g. Neuropeptide-Y, Short-neuropeptide F, and Allatostatin-A, and their receptors in the suppression of host-seeking and paternity enforcement in Aedes aegypti mosquitoes(Christ et al. 2017; Duvall et al. 2019; Fadda et al. 2019). Furthermore, it is becoming increasingly evident in vertebrates that 
an enteric nervous system (vagus nerve), also referred to as 'Second Brain'(Mayer 2011), not only mediates cross-talk between the gut and the brain but also establishes a bi-directional communication via gut-endosymbionts. This nexus of communication among the microbiota-gut-vagus-brain axis is crucial for maintaining metabolic homeostasis, mood, and perception(Forsythe and Kunze 2013; Ridaura and Belkaid 2015; Fülling et al. 2019). Blood meal significantly modulates metabolic energy homeostasis in the mosquito gut, but how the gut's nutrient-sensing mechanism influences brain function remains unknown(Lampe et al. 2019). Although blood-meal-induced gut-flora proliferation has been well demonstrated in mosquitoes(Romoli and Gendrin 2018), their neuromodulatory functions remain elusive.

Using a comprehensive RNA-Seq analysis of mosquito brain, coupled with extensive transcriptional profiling of neuro-modulators, comparative metagenomics analysis, and LC/MS-based quantitative estimation of neurotransmitters, here we demonstrated that fast blood meal engorgement and gutmetabolic switching (i) boost the brain's energy-metabolism, which may likely influence organismal homeostasis, and (ii) favor the rapid establishment of a bidirectional microbiome-gut-brain axis communication, where the gut may also serve as a secondary brain in the blood-fed mosquitoes. Our data suggest that this gut-brain-axis communication is crucial to guide and manage blood meal digestion, and egg development in Anopheles culicifacies mosquitoes, the dominant malaria vector in rural India. A strategy of impairing this communication could reveal an out-of-the-box technique to disrupt mosquito host-seeking and blood-feeding behavior.

\section{Material And Methods}

\section{A technical overview of the current investigation was represented graphically in Fig. S1 (supporting information).}

\section{Mosquito rearing and maintenance}

A cyclic colony of An. culicifacies mosquito, sibling species A was reared and maintained at $28 \pm 2{ }^{\circ} \mathrm{C}$ temperature and relative humidity of $80 \%$ in the central insectary facility of the ICMR-National Institute of Malaria Research. For routine rearing, adult female mosquitoes were fed on the rabbit. All protocols for rearing and maintenance of the mosquito culture were approved by the ethical committee of the institute.

RNA isolation and transcriptome sequencing analysis: For RNA-Seq analysis, the brain tissues were dissected from 0-1-day old, 30 min post-blood-fed, and $30 \mathrm{~h}$ post-blood-fed cold anesthetized $A n$. culicifacies mosquitoes by decapitation of the heads followed by application of gentle pressure over the head to pull out the brain tissue from the head cuticle and were collected in Trizol reagent. Then, total RNA was extracted from the collected brain tissues (approximately 30 mosquitoes were pooled to form one single sample), and a double-stranded cDNA library for each set of naïve, 30min, and 30h post-bloodfed was prepared by a prior well-established PCR-based protocol (Sharma et al. 2015). For transcriptome sequencing, the lllumina MiSeq 2 X 150 paired-end library preparation protocol was followed. Corresponding RNAseq data has been deposited to public repository NCBI, and freely accessible under Accession IDs: SRR9853884 (Ac-Br-SF); SRR9853885 (Ac-Br-BF-30Min), SRR9853883 (Ac-Br-BF-30hrs). 
Mosquito Gut metagenomics data are accessible under accession IDs: SRR12579422 (Ac-MG-SF); SRR12622557 (AC-MG-BF) at NCBI repository.

The bioinformatics data analysis pipeline is shown in Fig S1. Briefly, raw reads from each set were processed to remove the adaptors and low-quality bases $(<20)$. A de-novo clustering was used to build the final contigs/transcripts dataset using CLC Genomics Workbench (V6.2) (31) with default parameters (contig length $\geq 200$, Automatic word size: Yes, Perform Scaffolding: Yes, Mismatch cost: 2, Insertion cost: 3 , Deletion cost: 3 , length fraction: 0.5 , Similarity fraction: 0.8 ). Finally, the assembled transcriptome was used for CDS prediction and annotation using transdecoder software and BLASTX at e-value $1 \mathrm{e}^{-6}$ respectively. For a comprehensive differential gene expression analysis, we used the same protocol as mentioned previously (Sharma et al. 2015; De et al. 2018b). Additionally, to identify the differentially expressed genes associated with certain biological and molecular processes, we performed gene-list enrichment analysis using the Kobas 3.0 web server. The unique appearance of certain pathways in different brain samples was screened depending on the $p$-value $(<0.5)$.

\section{PCR-based gene expression analysis}

To establish the concept of the metabolic switch and inter-organ communication in mosquitoes, we targeted An. culicifacies brain, midgut, Malpighian tubule, and ovary tissues. The respective tissues were dissected and collected from both naïve sugar-fed and blood-fed mosquitoes originated from the same cohort at different time points. At first, the tissues were collected from 5-6-day old 25-30 naïve sugar-fed adult female mosquitoes. Next, adult female mosquitoes from the same cohort were offered blood-meal by offering a live animal (rabbit), and the desired tissues were collected as per the technical design of the experiments. In general, the fully engorged females were separated and kept in a proper insectary condition and the tissues were collected at the selected time points of post-blood-meal (PBM) such as 5min PBM, 2h PBM, 8-10h PBM, 24-30h PBM, 48h PBM, and 72h PBM from 25-30 mosquitoes for tissuespecific detailed expression analysis of the respective genes. The different tissues were pooled accordingly in Trizol and total RNA was extracted, followed by cDNA preparation. Differential gene expression analysis was performed using the normal RT-PCR and agarose gel electrophoresis protocols. For relative gene expression analysis, SYBR Green qPCR master mix and Biorad CFX 96 Real-Time PCR machine was used. PCR cycle parameters involved an initial denaturation at $95^{\circ} \mathrm{C}$ for $5 \mathrm{~min}, 40$ cycles of $10 \mathrm{~s}$ at $95^{\circ} \mathrm{C}, 15 \mathrm{~s}$ at $52^{\circ} \mathrm{C}$, and $22 \mathrm{~s}$ at $72^{\circ} \mathrm{C}$. Fluorescence readings were taken at $72^{\circ} \mathrm{C}$ after each cycle. The final steps of PCR at $95^{\circ} \mathrm{C}$ for 15 secs followed by $55^{\circ} \mathrm{C}$ for 15 secs, and again $95^{\circ} \mathrm{C}$ for 15 secs were completed before deriving a melting curve. Each experiment was performed in three independent

biological replicates for a better evaluation of the relative expression. The actin or Rps7 gene was used as an internal control in all the experiments, and the relative quantification was analyzed by the $2^{-\Delta \Delta C t}$ method(Livak and Schmittgen 2001), which was further statistically analyzed by applying the student ' $t$ ' test and two-way ANOVA. The detailed list of primer sequences used in the study is mentioned in Table S1. 
To unravel the origin of the oxidative stress response in the blood-fed brain, we performed reactive oxygen species (ROS) determination assay by incubating the brain tissue dissected from naïve and blood-fed mosquitoes with a $2 \mathrm{mM}$ solution of the oxidant-sensitive fluorophores, CM-H2DCFDA [5-(and6)-chloromethyl-29,79-dichloro-dichlorofluorescein diacetate, acetyl ester] (Sigma). After a 20-min incubation at room temperature in the dark, the brain tissues were washed thrice with PBS, and then transferred to a glass slide in a drop of PBS and checked the fluorescence intensity at wavelength 490 nm under a fluorescent microscope.

\section{Antibiotic treatment of mosquitoes}

To establish the concept of microbiome-gut-brain-axis communication, we disrupted the gut-commensal bacteria through antibiotic treatment. For the removal of gut bacteria, the pupae emerged in a washed and aseptic mosquito cage made up of muslin cloth. The antibiotic diet was provided to the newly emerged mosquitoes for $4-5$ days by mixing $10 \%$ sucrose solution with $10 \mu \mathrm{g}$ of penicillinstreptomycin/ml and $15 \mu \mathrm{g}$ gentamicin sulfate in it. To avoid any contamination, the antibiotic regimen was changed daily. After 4-5days of antibiotic treatment, blood-meal was provided to mosquitoes through the rabbit by maintaining proper sterile conditions such as (i) removed the extra hairs of rabbit pinnate/ears for easy access to blood meal, (ii) wipe the body of the rabbit with $70 \%$ ethanol, (iii) wipe the rabbit cage with $70 \%$ alcohol.

\section{Decapitation Experiment}

To test mosquito's gut ability to function as a second brain, we offered a blood meal to 5-6 days old naïve sugar-fed mosquitoes, and decapitated $\sim 100$ mosquitoes after one hour of blood-feeding. Next, the decapitated mosquitoes were securely kept back in the insectary for recovery. The head tissues were submerged in 1X PBS to avoid desiccation. As per the technical design, post decapitation, the percentage of mosquito's survival was recorded at different time points until we observed $100 \%$ mortality (mosquitoes that vibrate/move their legs or other body parts are considered as live and non-movable mosquitoes with visible shrinkage of the body parts at the respective time points are considered as dead). The brain and the gut tissues of surviving mosquitoes were dissected and collected at different time points for further gene expression analysis.

\section{Sample processing and MS analysis for neurotransmitter quantification}

For absolute quantification of neurotransmitters, mosquitoes were decapitated and brains pulled out from the head cuticle and quickly collected in an Eppendorf containing $50 \mu \mathrm{l}$ of $1 \%$ ascorbic acid and immediately freeze it. For each set, 60-65 mosquito brains or guts were pooled in a single tube. All samples were stored at $-80^{\circ} \mathrm{C}$ until further use. Each sample was extracted with $3 \mathrm{X}$ volume of extraction solvent. Samples were vortexed and refrigerated for 10-15 minutes at $4^{\circ} \mathrm{C}$. Samples were then subjected to sonication in a bath-type ultra-sonicator in pulses (twice, for $1 \mathrm{~min}$ each). Samples were then centrifuged at $14500 \mathrm{rpm}$ for 5 mins at $4^{\circ} \mathrm{C}$. The supernatants were separated and dried under a vacuum. 
Dried samples were spiked with internal standards (ISTDs) and derivatized, cleaned up, and prepared for LC-MS injections as per the protocol described earlier (Natarajan et al. 2015).

Briefly, Standards (STDs) were spiked in $200 \mu$ l of extraction solvent (acidic acetone ( $0.1 \%$ FA) containing $0.5 \mathrm{mM}$ ascorbic acid) and dried under vacuum. ISTDs were spiked to dried STDs, followed by the addition of $80 \mu \mathrm{L}$ borate buffer $(200 \mathrm{mM}, \mathrm{pH} 8.8)$ containing $1 \mathrm{mM}$ ascorbic acid. To the above mixture $10 \mu$ l of $0.1 \mathrm{~N} \mathrm{NaOH}$ was added, followed by the addition of AQC (from $1 \mathrm{mg} \mathrm{mL}-1$ stock). Samples were incubated at $55^{\circ} \mathrm{C}$ for $10 \mathrm{~min}$. The reaction was stopped by the addition of $500 \mu \mathrm{L}$ of acidic water $(0.1 \%$ FA). The derivatized standards were cleaned-up using the RP-SPE cartridges using the previously optimized protocol (Ramesh and Brockmann 2019)(Natarajan et al. 2015): activation with methanol, equilibration with water $(0.1 \% \mathrm{FA})$, loading of samples, washing (twice) with water ( $0.1 \% \mathrm{FA})$, and elution with acetonitrile: methanol (80:20) containing $2 \%$ FA. The eluate was dried under vacuum and reconstituted in $50 \mu \mathrm{L}$ of $0.5 \%$ acetonitrile. $10 \mu \mathrm{L}$ of reconstituted standards were injected for UHPLCMS/SRM analysis.

Data were acquired on a TSQ Vantage (triple stage quadrupole) mass spectrometer (Thermo Fisher Scientific, San Jose, CA, USA) coupled with an Agilent 1290 Infinity series UHPLC system (Agilent Technologies India Pvt. Ltd.). The UHPLC system was equipped with a column oven (set at $40^{\circ} \mathrm{C}$ ) and a thermo-controller for maintaining the auto-sampler at $10^{\circ} \mathrm{C}$. A C-18 column $(2.1 \times 100 \mathrm{~mm}, 1.8 \mu \mathrm{m}$, Agilent, Inc.) was used to perform the separation. The mobile phase solvent $A$ was $10 \mathrm{mM}$ ammonium acetate in water containing $0.1 \%$ formic acid, and solvent $B$ was acetonitrile containing $0.1 \%$ formic acid. The gradient was optimized to get maximum separation (2\% B at $0 \mathrm{~min}, 2 \% \mathrm{~B}$ at $3 \mathrm{~min}, 20 \% \mathrm{~B}$ at $20 \mathrm{~min}, 35 \%$ $\mathrm{B}$ at $25 \mathrm{~min}, 80 \% \mathrm{~B}$ at $25-27 \mathrm{~min}, 2 \% \mathrm{~B}$ at $27-35 \mathrm{~min}$ ) at a flow rate of $200 \mu \mathrm{L} \mathrm{min}-1$. The operating conditions were as follows: ionization mode: positive; spray voltage: $3700 \mathrm{~V}$; capillary temperature: $270^{\circ} \mathrm{C}$; source temperature: $80^{\circ} \mathrm{C}$; sheath gas: 30 (arbitrary units); auxiliary gas: 10 (arbitrary units); collision gas: argon. Parent and product masses, S-lens voltages, and collision energies were used as per the previously optimized method (Natarajan et al. 2015; Ramesh and Brockmann 2019).

Metagenomics analysis \& microbiome profiling: For the metagenomics study, we collected gut from 3-4 days old sugar-fed adult female mosquitoes $(n=50)$. While for blood-fed mosquito gut samples, 3-4 days old adult female mosquitoes from the same cohort were provided blood-meal by offering a live animal (rabbit), and midguts were collected after 24-30 hrs of blood-feeding. Before dissection, the mosquitoes were surface sterilized with $70 \%$ ethanol for $1 \mathrm{~min}$ in the highly sterilized condition of the Laminar airflow, and dissected tissues were collected in 1X Saline Tris-EDTA (100 mM NaCl/10 mM Tris$\mathrm{HCl}, \mathrm{pH}$ 8.0/1 mM EDTA, pH 8.0) buffer. At least 50 whole guts either from naïve sugar-fed or blood-fed mosquitoes, originating from the same cohort were collected into the minimal volume $(20 \mu \mathrm{l})$ of sterile icecold 1X STE and whole DNA was extracted as described earlier(Sharma et al. 2020). The quality of extracted genomic DNA (gDNA) was checked by loading the $5 \mu$ l aliquot on $1 \%$ agarose gel under the condition of $110 \mathrm{~V}$ for $30 \mathrm{~min} .1 \mu \mathrm{l}$ of each sample was loaded in NanoDrop 8000 for determining the $A_{260 / 280}$ ratio. The DNA was quantified using the Qubit dsDNA BR Assay kit (Thermo Fisher Scientific Inc.). $1 \mu \mathrm{l}$ of each sample was used for determining concentration using Qubit ${ }^{\circledR} 2.0$ Fluorometer. For the 
preparation of amplicon libraries, V3-V4 hyper-variable region primers were used according to the library preparation protocol for the $16 \mathrm{~S}$ Metagenomic Sequencing. The library for the sequenced fragments was obtained as per the standard Illumina protocol. Corresponding gut metagenomics data has been deposited to public repository NCBI, and freely accessible under accession IDs: SRR12579422 (Ac-MGSF); SRR12622557 (Ac-MG-BF). QIIME software was used for maximum-likelihood phylogeny inference(Kuczynski et al. 2011), generating OTUs for taxonomic identification and diversity estimation was performed using Megan software(Huson et al. 2007) (Table S2, Fig. S2). To validate the metagenomics data, the abundancy of the selected bacterial species was profiled through Real-Time PCR as described earlier(Sharma et al. 2020).

\section{Results}

\section{Hypothesis}

Several independent studies highlighted the impact of age, sex, and circadian rhythm on the olfactory derived host-seeking behavioral properties of different mosquito species(De et al. 2018b; Omondi et al. 2019; Tallon et al. 2019). However, a holistic understanding that how a coordinated action of the neuroolfactory system influences the host-seeking, and blood-feeding behavioral properties of the adult female mosquitoes, remains unresolved. Since the neuro-system is highly sensitive and versatile centre for chemical information exchange, we hypothesize that a minor change in the innate physiological status may have a strong impact on the mosquito's everyday life. Importantly, after blood meal ingestion, a drastic change in the innate physiological status of the gut metabolic machinery i.e. "gut metabolic switch", may trigger brain to drive the engagement of multiple organs. This unusual, and condtional modulation of brain action is crucial to successfully manage the complex process of gonotrophic cycle.. Therefore, it is very much plausible to propose that fast engorgement of mosquito gut with blood meal may shift mosquitoes' brain functions from external communication to inter-organ management, such as (a) initiation of diuresis; b) finding a resting site for digestion of blood meal in the midgut; (c) distribution of amino acids, generated through the degradation of protein-rich blood meal; (d) active engagement of the fat body and ovary for egg maturation and life cycle maintenance (Fig. 1). We recently demonstrated that both mating and circadian rhythm have an important role in driving olfactory guided pre-blood-mealassociated behavioral properties in the aging adult female mosquito An. culicifacies(De et al. 2017, 2018b; Das De et al. 2018). Aligning to olfactory responses, here, we aimed to decode and establish a possible molecular correlation between brain and gut-metabolic switch, and desgined a similar RNA-Seq strategy (Fig. 1),, in the mosquito An. culicifacies.

\section{Blood meal ingestion boosts the brain's energy metabolism}

A comparative RNA-Seq data analysis of naïve sugar-fed, $30 \mathrm{~min}$, and $30 \mathrm{~h}$ post-blood-fed mosquito's brain showed a gradual suppression of brain-specific transcript abundance (Fig. 2a). Surprisingly, we also observed an exceptional enrichment of oxidation-reduction process associated transcripts in response to blood-feeding (Fig. 2b) (Table S3a, S3b). Though, we failed to detect any signal of oxidative stress in a 
$2 \mathrm{mM}$ solution of the oxidant-sensitive fluorophores, CM-H2DCFDA (data are not shown), but we observed an enrichment of several mitochondrial activity proteins such as 2-oxoglutarate dehydrogenase, NADH dehydrogenase, glutathione peroxidase, etc. A comparative metabolic pathway prediction analysis further confirmed the exclusive induction of several unique pathways linked to (a) energy metabolism, (b) neurotransmitter synthesis, and (c) neurite outgrowth and synaptic transmission (Fig. 2c). Together these data indicated that blood meal-associated gut metabolic switch may trigger a "hyper energy" state, and alter the expression of neuro-modulatory factors in the mosquito brain.

To verify the above presumption, we profiled and compared the expression pattern of the PGC-1 gene (Peroxisome proliferator-activated receptor gamma coactivator 1-alpha), an important transcriptional coactivator that regulates genes involved in energy metabolism(Lin et al. 2005; Liang and Ward 2006; Austin and St-Pierre 2012). A persistent elevation of PGC-1 ( $P \leq 0.009$ at $8 \mathrm{~h}$ PBM, $P \leq 0.007$ at $30 \mathrm{~h}$ PBM), and a parallel enrichment of glycolysis and TCA cycle gene pyruvate kinase $(P \leq 0.0176)$ and oxoglutarate dehydrogenase $(P \leq 0.0019)$ respectively, indicated an enhanced mitochondrial activity in the brain of blood-fed mosquitoes (Fig. 2d, e). Next, we tested whether the amino acids generated through blood meal digestion or trehalose, a non-reducing disaccharide, acts as raw material for the brain's energy metabolism. Although trehalose serves as a primary energy source in the insects' brain(Shukla et al. 2015; Mattila and Hietakangas 2017), we observed a sequential increment in the amino acid transporter $(P \leq 0.0515)$ as well as trehalose $(P \leq 0.0071)$ transporter genes in the blood-fed brain (Fig. 2f). Together, these data indicate that both amino acids and trehalose moities may synergistically communicate the nutritional signal to the brain for active management of multi-organ communication(Gulia-Nuss et al. 2011; Hou et al. 2015).

\section{Spatial and temporal modulations of neuro-signaling influences metabolic switch-associated physiological activities}

In naive sugar-fed mosquitoes, olfactory guided neuro-signaling and the brain's energy consumption is optimal to drive external stimuli associated with routine behavioral events like flight, mating, and hostseeking. Recently, we have demonstrated that prior host-exposure sex, and circadian have a significant impact on the olfactory responses in the aging adult-female An. culicifacies mosquito (De et al. 2017, 2018b; Das De et al. 2018). Likewise, to test and evaluate the possible correlation of age with neuroregulation, we monitored the expression profile of at least 14 neuro-modulatory genes in aging naïve adult female mosquito's brain (Fig. S3). A limited modulation of expression suggested that the first exposure to the host may have an important role in cognitive learning, and blood-feeding behavioral adaptation in mosquitoes, though further studies are needed to clarify and establish this correlation. However, surprisingly, after blood feeding an increase in the brain's energy consumption, prompted us to test the functional correlation of the brain with gut metabolic switch activities. Here, we hypothesize that blood meal uptake may temporarily pause the external communication, and increased energy state possibly may favor the shifting of the brain's engagement for the maintenance of organismal homeostasis. Thus, we identified and shortlisted transcripts encoding proteins, likely involved in the key events of the synaptic signal transmission process, i.e., crucial for the brain's functioning (Fig. 3a). 
Thereafter, we evaluated the blood-meal-associated transcriptional response of selected transcripts regulating either receptor-mediated neuronal or cellular signaling processes during synaptic transmission (Fig. 3a).

Surprisingly, we observed a limited change in the expression of neurotransmitters and biogenic amine receptor genes such as serotonin receptor, dopamine receptor, octopamine receptor, and GABA receptor, etc. in response to blood-meal (Fig. 3b). While, on the contrary, cellular signal transduction proteins such as cGMP protein kinase, phospholipase C, GABA gated chloride channel, and serine-threonine protein kinase, exhibited a significant modulation in response to metabolic switch (Fig. 3c). Together, these findings support the idea that a rapid blood meal ingestion may drive brain engagement to manage metabolic switch-associated activities and distant organs' function (Fig. 3d).

\section{Innate physiological status differentially modulates tissue-specific neuromodulators/receptors transcripts expression}

To further validate and correlate brain-inter-organ communication, we monitored the temporal and spatial expression of at least 21 key genes (Table 1) having the blood-meal-associated function in their targeted tissue such as midgut (MG), ovary (Ov), and Malpighian tubules (MT). Notably, we observed a significant upregulation of ILP3 $(p<0.0002)$, and also time-dependent modulation of other neuropeptides

(Neuropeptide Y, Leukokinin) and neuro-hormones (OEH, DH44, and ARMAA) in the blood-fed mosquitoes brain (Fig. 4a, b, c). We correltes that a gradual induction of ILP3 synthesis and OEH secretion from the brain's neurosecretory cells may activate the ovaries for the synthesis of ecdysteroids to initiate the vitellogenesis process (Brown et al. 2008; Vogel et al. 2015; Sharma et al. 2019). A transient increase in NRY immediately after blood-feeding may be due to gut distension, but a significant increase $(P<0.005)$ after $24 \mathrm{~h}$ and $72 \mathrm{~h}$ may cause suppression of host-seeking, a mechanism recently reported in Aedes aegypti(Liesch et al. 2013; Duvall et al. 2019). 
Table 1

Details of the selected transcripts used to understand inter-organ communication during metabolic switch events

\begin{tabular}{|c|c|c|c|c|c|}
\hline $\begin{array}{l}\text { SI. } \\
\text { No. }\end{array}$ & Gene Name & $\begin{array}{l}\text { Synthesized } \\
\text { From }\end{array}$ & $\begin{array}{l}\text { Target } \\
\text { Tissue }\end{array}$ & Possible Function & $\begin{array}{l}\text { Target } \\
\text { Tissue for } \\
\text { Expression } \\
\text { study }\end{array}$ \\
\hline 1. & ILP1 & $\begin{array}{l}\text { MNSC of } \\
\text { brain }\end{array}$ & Ovary & $\begin{array}{l}\text { Halt ovarian maturation } \\
\text { (Sim and Denlinger 2009) }\end{array}$ & $\begin{array}{l}\text { Brain, } \\
\text { midgut }\end{array}$ \\
\hline 2. & ILP3 & $\begin{array}{l}\text { MNSC of } \\
\text { brain }\end{array}$ & $\begin{array}{l}\text { Midgut, } \\
\text { Ovary, Fat } \\
\text { Body, } \\
\text { Hemocyte }\end{array}$ & $\begin{array}{l}\text { Nutrient storage by FB, } \\
\text { regulation of digestive } \\
\text { enzymes by MG, } \\
\text { Ecdysteroid production } \\
\text { from ovaries, the immune } \\
\text { response by HC (Castillo et } \\
\text { al. 2011; Badisco et al. } \\
\text { 2013; Sharma et al. 2019) }\end{array}$ & $\begin{array}{l}\text { Brain, } \\
\text { midgut }\end{array}$ \\
\hline 3. & Leucokinin & $\begin{array}{l}\text { Abdominal } \\
\text { ganglia }\end{array}$ & $\begin{array}{l}\text { Gut, } \\
\text { Malpighian } \\
\text { tubule }\end{array}$ & $\begin{array}{l}\text { Regulation of fluid } \\
\text { secretion, ionic balance } \\
\text { (Kersch and Pietrantonio } \\
\text { 2011) }\end{array}$ & Brain \\
\hline 4. & $\begin{array}{l}\text { PTTH - } \\
\text { Prothoracicotropic } \\
\text { Hormone }\end{array}$ & Brain & Not Known & $\begin{array}{l}\text { Diapause and blood- } \\
\text { feeding (Zhang and } \\
\text { Denlinger 2011) }\end{array}$ & Brain \\
\hline 5. & $\begin{array}{l}\text { Neuropeptide Y } \\
\text { Receptor -NRY }\end{array}$ & $\begin{array}{l}\text { NSC of } \\
\text { brain }\end{array}$ & Brain & $\begin{array}{l}\text { Host-seeking inhibition } \\
\text { (Liesch et al. 2013; Duvall } \\
\text { et al. 2019) }\end{array}$ & Brain \\
\hline 6. & $\begin{array}{l}\text { Leucokinin } \\
\text { Receptor }\end{array}$ & $\begin{array}{l}\text { Multiple } \\
\text { tissues }\end{array}$ & $\begin{array}{l}\text { Multiple } \\
\text { tissues }\end{array}$ & $\begin{array}{l}\text { Regulation of fluid } \\
\text { secretion, ionic balance } \\
\text { (Strand et al. 2016) }\end{array}$ & $\begin{array}{l}\text { Brain, } \\
\text { midgut }\end{array}$ \\
\hline 7. & $\begin{array}{l}\text { Diuretic hormone } \\
44(\mathrm{DH} 44)\end{array}$ & $\begin{array}{l}\text { Gut } \\
\text { endocrine } \\
\text { cells }\end{array}$ & $\begin{array}{l}\text { Malpighian } \\
\text { tubule }\end{array}$ & $\begin{array}{l}\text { Regulation of diuresis } \\
\text { (Piermarini et al. 2017) }\end{array}$ & $\begin{array}{l}\text { Brain, } \\
\text { midgut }\end{array}$ \\
\hline 8. & $\begin{array}{l}\text { OEH - Ovary } \\
\text { Ecdysteroidogenic } \\
\text { Hormone }\end{array}$ & $\begin{array}{l}\text { MNSC and } \\
\text { ventricular } \\
\text { ganglia of } \\
\text { the brain }\end{array}$ & Ovary & $\begin{array}{l}\text { Induces ecdysone } \\
\text { production from the ovary } \\
\text { after blood feeding (Strand } \\
\text { et al. 2016) }\end{array}$ & Brain \\
\hline 9. & $\begin{array}{l}\text { ARMAA - } \\
\text { Aromatic-L-amino- } \\
\text { acid } \\
\text { decarboxylase }\end{array}$ & $\begin{array}{l}\text { Multiple } \\
\text { tissues }\end{array}$ & $\begin{array}{l}\text { Multiple } \\
\text { tissues }\end{array}$ & $\begin{array}{l}\text { Synthesis of serotonin } \\
\text { neurotransmitter and } \\
\text { regulation of multiple } \\
\text { physiological processes }\end{array}$ & Brain \\
\hline 10. & DH44R1 & $\begin{array}{l}\text { Malpighian } \\
\text { tubule }\end{array}$ & $\begin{array}{l}\text { Malpighian } \\
\text { tubule }\end{array}$ & $\begin{array}{l}\text { Regulation of Diuresis } \\
\text { (Strand et al. 2016; } \\
\text { Piermarini et al. 2017) }\end{array}$ & $\begin{array}{l}\text { Midgut } \\
\text { and } \\
\text { Malpighian } \\
\text { tubule }\end{array}$ \\
\hline
\end{tabular}




\begin{tabular}{|c|c|c|c|c|c|}
\hline $\begin{array}{l}\text { Sl. } \\
\text { No. }\end{array}$ & Gene Name & $\begin{array}{l}\text { Synthesized } \\
\text { From }\end{array}$ & $\begin{array}{l}\text { Target } \\
\text { Tissue }\end{array}$ & Possible Function & $\begin{array}{l}\text { Target } \\
\text { Tissue for } \\
\text { Expression } \\
\text { study }\end{array}$ \\
\hline 11. & $\begin{array}{l}\text { CCHamide } \\
\text { Receptor } 2\end{array}$ & $\begin{array}{l}\text { CCHamide2 } \\
\text { synthesized } \\
\text { from gut } \\
\text { endocrine } \\
\text { cells }\end{array}$ & $\begin{array}{l}\text { Multiple } \\
\text { tissues }\end{array}$ & $\begin{array}{l}\text { Nutrient dependent } \\
\text { regulation of ILPs from } \\
\text { brain (Strand et al. 2016) }\end{array}$ & Midgut \\
\hline 12. & $\begin{array}{l}\text { 5HTR - Serotonin } \\
\text { Receptor }\end{array}$ & $\begin{array}{l}\text { Multiple } \\
\text { tissues }\end{array}$ & $\begin{array}{l}\text { Multiple } \\
\text { tissues }\end{array}$ & $\begin{array}{l}\text { Multiple behavioral and } \\
\text { physiological processes } \\
\text { (Kinney et al. 2014; Ling } \\
\text { and Raikhel 2018) }\end{array}$ & Midgut \\
\hline 13. & $\begin{array}{l}\text { Glutamate R - } \\
\text { Glutamate } \\
\text { Receptor }\end{array}$ & $\begin{array}{l}\text { Multiple } \\
\text { tissues }\end{array}$ & $\begin{array}{l}\text { Multiple } \\
\text { tissues }\end{array}$ & $\begin{array}{l}\text { Olfactory ionotropic } \\
\text { glutamate receptor in } \\
\text { odorant recognition } \\
\text { (Identified from AC brain } \\
\text { transcriptome data) (Chen } \\
\text { et al. 2017b) }\end{array}$ & Midgut \\
\hline 14. & $\begin{array}{l}\text { Glycine R - Glycine } \\
\text { Receptor }\end{array}$ & $\begin{array}{l}\text { Multiple } \\
\text { tissues }\end{array}$ & $\begin{array}{l}\text { Multiple } \\
\text { tissues }\end{array}$ & $\begin{array}{l}\text { Inhibit neurotransmission } \\
\text { (Identified from AC brain } \\
\text { transcriptome data) } \\
\text { (Bowery and Smart 2006) }\end{array}$ & Midgut \\
\hline 15. & $\begin{array}{l}\text { Akt Kinase - } \\
\text { Protein kinase B }\end{array}$ & $\begin{array}{l}\text { Fat body, } \\
\text { ovary }\end{array}$ & Ovary & $\begin{array}{l}\text { Activation of TOR pathway } \\
\text { (Badisco et al. 2013) }\end{array}$ & Ovary \\
\hline 16. & $\begin{array}{l}\text { CYP31A41-20E } \\
\text { hydroxylase (20E } \\
\text { synthesizing } \\
\text { enzyme) }\end{array}$ & Ovary & $\begin{array}{l}\text { Fat body } \\
\text { and ovary }\end{array}$ & $\begin{array}{l}\text { Ovary and oocyte } \\
\text { development (Hansen et al. } \\
\text { 2014) }\end{array}$ & Ovary \\
\hline 17. & $\begin{array}{l}\text { STPK - Serine } \\
\text { threonine-protein } \\
\text { kinase }\end{array}$ & Multiple & Multiple & $\begin{array}{l}\text { Multiple physiological } \\
\text { processes (Arsic and Guerin } \\
2008 \text { ) }\end{array}$ & Ovary \\
\hline 18. & PI4-Kinase & Multiple & Multiple & $\begin{array}{l}\text { Multiple physiological } \\
\text { processes (Identified from } \\
\text { AC brain transcriptome } \\
\text { data) }\end{array}$ & Ovary \\
\hline 19. & $\begin{array}{l}\text { Calcitonin } \\
\text { Receptor }\end{array}$ & $\begin{array}{l}\text { Malphigian } \\
\text { tubule }\end{array}$ & $\begin{array}{l}\text { Malphigian } \\
\text { tubule }\end{array}$ & $\begin{array}{l}\text { Regulation of diuresis } \\
\text { (Coast 2005; Piermarini et } \\
\text { al. 2017) }\end{array}$ & $\begin{array}{l}\text { Malphigian } \\
\text { tubule }\end{array}$ \\
\hline 20. & $\begin{array}{l}\text { KDNaCa } \\
\text { Exchanger }\end{array}$ & $\begin{array}{l}\text { Malpighian } \\
\text { tubule }\end{array}$ & $\begin{array}{l}\text { Malpighian } \\
\text { tubule }\end{array}$ & $\begin{array}{l}\text { Regulate fluid secretion and } \\
\text { diuresis (Piermarini et al. } \\
\text { 2017) }\end{array}$ & $\begin{array}{l}\text { Malpighian } \\
\text { tubule }\end{array}$ \\
\hline 21. & V-Type ATPase & $\begin{array}{l}\text { Malpighian } \\
\text { tubule }\end{array}$ & $\begin{array}{l}\text { Malpighian } \\
\text { tubule }\end{array}$ & $\begin{array}{l}\text { Regulate membrane } \\
\text { potential and diuresis } \\
\text { (Piermarini et al. 2017) }\end{array}$ & $\begin{array}{l}\text { Malpighian } \\
\text { tubule }\end{array}$ \\
\hline
\end{tabular}


Next, we asked how the dynamic changes of the neuromodulators in the blood-fed brain influence distant organ responses, such as diuresis regulation by the Malpighian tubule, blood digestion process in the midgut, and oocyte maturation in the ovary. Transcriptional profiling of selected neuropeptide, neurotransmitter receptor transcripts (Table 1 ) indicated that blood meal triggers an immediate and prolonged ( 48h PBM) impact on the expression of the gut-neuro transcript (Fig. 4d). Parallel observation of an early induction (2h PBM) of serine threonine-protein kinase (MAPK activated protein kinase) and late expression of Akt kinase (48h PBM) in the ovary suggested a controlled regulation of the nutritional signaling pathway favors the vitellogenesis process (Fig. 4e) (Arsic and Guerin 2008; Badisco et al. 2013). Likewise, observation of a unique pattern of diuretic hormone (8h PBM) and potassium dependent sodium-calcium exchanger gene (24h PBF) expression in the Malpighian tubule suggested an active diuresis process until 24h post blood meal (Fig. 4f) (Piermarini et al. 2017).

\section{Gut, the 'second brain' communicates the nutritional status through neurotransmitter synthesis}

In vertebrates and also in the fruit flies, it is well evident that effective communication between the gut and brain has a paramount effect in shaping optimal health(Mayer 2011; Fülling et al. 2019), but a very limited knowledge exists in the mosquitoes(Gulia-Nuss et al. 2011). Prolonged modulation of the neuromodulators expression in the blood-fed mosquitoes' gut invigorates us to presume the existence of bi-directional gut-brain axis communication. An enriched expression pattern of neurotransmitter receptor genes, even after decapitation, reflected that the gut may also perform neuro-modulatory actions independently (Fig. S3). To further establish a proof-of-concept, we followed LC/MS-based absolute quantification of different neurotransmitters (NT) and compared their levels in the brain as well as in the gut of naïve and blood-fed mosquitoes.

Our data revealed that in naïve sugar-fed mosquitoes, although the brain serves as the primary source of NT synthesis, the midgut also synthesizes a substantial amount of NTs (Fig. 5a). However, blood-feeding causes a drastic shift in the NTs level in the midgut than in the brain (Fig. b, c). Notably, we observed an unpredictable increase in most NTs except glutamic acid, tyrosine, and tyramine in the gut (Fig. 5c). Whereas, the brain tissue showed a notable decrease in the majority of the NTs synthesis, except for histamine, tyrosine, and tryptophan (Fig. 5b). We also observed that tyrosine amino acid was exclusively induced in the brain after blood-feeding, but remained below the threshold level in the gut (Fig. 5b, c). Although our data support previous studies that in addition to the brain, the gut also serves as a major source of multiple neurotransmitters in vertebrates and fruit fly(Mayer 2011; Solari et al. 2017), the mechanism of nutrition-dependent NTs modulation remains unclear. Especially, in mosquitoes our understanding of the complex nature of blood meal digestion and gut-brain axis communication is obscure. Thus, our unusual observation of a thousand-fold increase in the levels of histidine, serine, aspartic acid, and tryptophan in the blood-fed mosquito's gut emanated few key questions: 1) whether increased levels of amino acids in the gut during blood meal digestion may act as an NT? 2) Do bloodmeal-induced proliferation of the gut microbiota has any effect on NT dynamics? 3) Do the gut endosymbionts of mosquitoes have any impact on gut-brain axis communication? (Fig. 5d). 


\section{Symbiotic gut flora influences gut-brain axis communication}

The mechanism of gut-brain axis communication in vertebrates primarily involves neuronal stimulation through the vagus nerve, where endosymbionts play key role in the regulation of the gut endocrine system, and associated biochemical pathways (Forsythe and Kunze 2013; Oriach et al. 2016; Fülling et al. 2019). Previous literature suggests that mosquito gut endosymbionts regulate many biological functions such as mosquito immunity, blood meal digestion, and ecological adaptation(Guégan et al. 2018; Ling and Raikhel 2018). Ingestion of protein-rich blood meal favors the rapid enrichment of gut microbiota(Romoli and Gendrin 2018), but whether it affects the nexus of communication between the gut and brain remains elusive.

Therefore, to uncover the gut microbiome complexity, and establish their possible relations with neurotransmitter abundancy, we evaluated the nature and diversity of gut microbiome population dynamics alteration in response to blood-feeding. A comparative metagenomic analysis revealed that the naïve sugar-fed mosquito harbors $90 \%$ of the Enterobacteriaceae family of gram-negative gammaproteobacteria such as Enterobacter cloacae complex sp., Chonobacter sp., Escherichia coli; $6 \%$ Psedomonodales family of gram-negative gamma-proteobacteria such as (a) Acinetobacter $s p$. members e.g. Acinetobacter guillouiae, Acinetobacter iwoffii, (b) Pseudomonas aeruginosa sp. group e.g. Pseudomonas alcaligenes, $P$. nitroreducens, $P$. veronii, $P$. stutzeri and $P$. viridiflava; and other bacterial family members of Bacteroidetes e.g. Flavobacteriacae - Chryseobacterium sp., Elizabethkingia meningospetica; beta-proteobacteria-Alcaligenaceae- Alcaligenes faecalis (Fig. 6/ Fig. S4a, b, c). Furthermore, we also observed that blood-feeding not only suppresses Enterobacteriaceae family member by $50 \%$, but favors rapid proliferation of Pseudomonadales to $46 \%$ of the total community, where we observed dominant association of Pesudomonas sp., Acinetobacter johnsonii; Acinetobacter rhizosphaerae, and other members from Alpha-proteobacteria family such as Sphingobium sp., Gluconacetobacter diazotrophicus, Achromobacter sp., Sphingomonas azotifigens, Methylobacterium sp. as well as Beta-proteobacteria-Burkholderiales family members such as Acidovorex sp., Delftia ramlibacter, Janthinobacterium lividum (Fig. S4a, b, c). Our microbial profiling data further suggested that blood meal significantly alters the abundance of the gram-negative bacteria such as Pseudomonas and Elizabethkingia (Fig. 6), compared to gram-positive e.g. Agromonas and Rubrobacter(Actiobacteria) (Fig. S5).

Although the correlation of microbiome-gut-brain axis communication in the blood-feeding mosquitoes is yet not fully established, however, we opined that amino-acids resulting from rapid digestion of proteinrich blood meal, and its metabolite products may serve as an additional potent source of neuromodulators(1999). Here, our observation of Enterobacteriaceae family member abundancy and low NTs level in the gut than the brain of naïve sugar-fed mosquitoes indicate the basal-level of gut-brain-axis communication is enough to maintain physiological homeostasis. However, a rapid proliferation of Pseudomonadales family members, and a multi-fold enrichment of NTs in the gut, while mild suppression of the majority of NTs in the brain except for Histamine, Tyrosine and Tryptophan of the 
blood feed mosquitoes suggests that members of Pseudomonas species, may likely have a neuromodulatory role in protein-rich diet-induced gut-brain-axis communication.

To further strengthen our hypothesis, we tested and evaluated the effect of gut flora removal on the neurotransmitters dynamics. We performed an absolute quantification of the potent neuroactive molecules, and compared their levels in the gut and brain of the naïve and antibiotic-treated mosquitoes. A significant elevation of tryptophan and consequent downregulation of serotonin levels in both the gut and brain of aseptic non-blood fed mosquitoes (Fig. 7a, b), corroborate with the previous observations that depletion of microbial flora may significantly delimit the de-novo-synthesis of serotonin, resulting in increased tryptophan concentration in the gut and brain(O'Mahony et al. 2015). Additionally, we also observed that antibiotic treatment not only caused a notable increase in histidine and histamine levels in both the gut and brain, also favored an exclusive induction of Dopa, and significant enrichment of GABA in the gut of the aseptic mosquitoes (Fig. 7a, b).

Together, these data indicated that gut bacteria removal may also influence the systemic level of amino acid concentration in naïve mosuitoes (Fig. 7a, b).

To understand how blood-feeding influences gut-brain axis communication, we requantified and compared the level of the neurotransmitters of naïve and antibiotic-treated blood-fed mosquitoes. A similar pattern of NTs synthesis was observed in both naïve blood-fed and antibiotic-treated blood-fed mosquitoes, but the level of modulation gets heightened in antibiotic-treated blood-fed gut and brain (Fig. S7, Table S4). To further support the above observation, we also monitored and compared the expression patterns of neurotransmitter receptor genes (Glycine R, glutamate R, serotonin R, dopamine R), insulinlike-peptide, and one of the junction protein gene (lachesin) in the gut and brain of naïve vs. antibiotictreated mosquitoes (Fig. 7c). Consistent with NT quantitative data, the respective receptor genes also showed a significant difference in their abundance throughout the gut-brain axis. We also noticed a differential expression pattern of ILP3, ARMAA (Aromatic-L-amino-acid decarboxylase/serotonin synthesizing enzyme), and lachesin transcript between naïve and antibiotic-treated mosquitoes undergoing metabolic switch event (Fig. 7c).

With our current data, we propose that a bi-directional gut-brain axis communication may exist to manage complex gut immune-physiological responses via gut-microbiome association during the blood meal digestion process in gravid females. Although, it is yet to be established as on how this cross-talk directly influences brain-specific responses such as mood and cognition.

\section{The mosquito brain maintains basal immunity}

The immune system plays a crucial role in maintaining brain health by protecting it from both external and internal stress(Aguilera et al. 2018). Since the central nervous system and the immune system are the most energy-consuming organs, we consider that the immune system may play an important role to overcome blood-meal-induced metabolic stress, such as oxidative stress, osmotic stress, and elevated levels of dietary heme molecules. To trace the possible linkage of the brain-immune function, we 
identified and cataloged a total of 913 immune transcripts from brain tissue transcriptome data (Fig. 8a). Among the 18 classified immune family proteins, autophagy, CLIP-domain serine proteases, and peroxidases were observed the most predominant, accounting for more than $50 \%$ of the total immune transcripts. Furthermore, a comparative transcript abundance analysis showed that blood meal may cause a moderate change in the immune transcript expression (Fig. 8b). Increased percentage of peroxidases and CLIP-domain serine protease transcripts in the blood-fed brain suggested that these immune transcripts may prevent brain tissue from oxidative stress-induced damage and facilitate its recovery (Fig. 8b). Further, functional analysis of the immune transcripts in the central nervous system may unravel the novel regulatory mechanism of the immune genes to maintain the brain in shape.

\section{Discussion}

Host-seeking and blood-feeding behavior evolution make it difficult to resolve the complexity of decisionmaking neuro-actions in hematophagous insects(Das De and Dixit 2020). Recently, Benjamin J. Matthews et. al., cataloged hundreds of genes that are differentially expressed in the blood-fed brain(Matthews et al. 2016), of which the brain-encoded neuropeptide $Y$ has been suggested to play a crucial role in host-seeking suppression following blood feeding(Duvall et al. 2019). But, in-depth analysis of the gut-metabolic-switching, and modulation of brain function is unexplored. Our study attempts to establish a molecular relationship of gut-brain-axis (GBA) communication, and explore a possible functional correlation of gut-endosymbionts on neuro-transmitters dynamics influencing GBA communication.

\section{Gut-metabolic switch modulates the brain's energy metabolism and functional engagement}

To understand that how the engorgement of the gut with blood meal modulate brain functioning, we performed a comparative RNA-Seq analysis of naïve sugar-fed and blood-fed of adult female mosquitoes' brain in An. culicifacies. In contrast to the pre-blood meal olfactory responses, which are significantly influenced by age/sex/circadian even in the absence of host-exposure(De et al. 2017, 2018b; Das De et al. 2018), we did not observe any significant alteration of neuro-modulator genes expression in the non-blood-fed (host-unexposed) aging An. culicifacies mosquitoes. The onset of host-seeking behavior coincides with the age-dependent gradual change in the relative abundance of gene transcripts and increase in sensitivity of the olfactory sensory neurons (OSNs), where older females are likely to be more responsive to salient human odorants, and hence active host-seeker than teneral young female mosquitoes(Omondi et al. 2019; Tallon et al. 2019). Thus, our observation of a limited change in the neuro-modulatory genes expression in the mosquito An. culicifacies, suggests that cognitive learning and memory response towards host-attraction are poorly developed until mosquitoes are exposed to hosts.

Post-blood-feeding an exclusive induction of oxidation-reduction family proteins and a comparative pathway analysis predicts that blood meal may enhance the brain's energy metabolic activities. Shreds of evidence from Drosophila, vertebrates, and limited studies in mosquitoes also suggest that altered metabolic physiology influences the cross-talk between the brain, and peripheral tissues for the 
maintenance of systemic energy homeostasis(Droujinine and Perrimon 2016; Oriach et al. 2016; Roh et al. 2016; Mattila and Hietakangas 2017; Plaçais et al. 2017; Yellen 2018). To perform this action, continuous neuronal stimulation is required, which consequently increases the energy demand of the brain(Volkenhoff et al. 2015; Yellen 2018). An enrichment of the fructose-mannose metabolic pathway, and persistent elevation of PGC-1 and oxoglutarate dehydrogenase gene provides evidence of escalated energy metabolism and enhanced mitochondrial activity in blood-fed mosquitoes brain(Lin et al. 2005; Austin and St-Pierre 2012). In this context, it is plausible to propose that hyper mitochondrial activity may increase the ROS level which could have a deleterious impact on neuro action. Our observation of the unique appearance of the pentose phosphate pathway and glutathione peroxidase transcript (Oxidationreduction category gene), along with the upregulation of CLIP-domain serine proteases and peroxidases immune transcripts may attribute to the scavenging of ROS generated due to enhanced mitochondrial activity. Moreover, blood-meal-induced expression of amino acid transporters and trehalose transporter indicated that both trehalose and amino acids may serve as a raw material for enhanced energy metabolism. Furthermore, we also observed a significant alteration of transcripts involved in intracellular signaling than neurotransmitter receptors in the blood-fed mosquitoes' brains. Taken together, we hypothesize that an internal nutritional stimulus may shift brain engagement from external communication to inter-organ management, which requires a rapid and continuous synaptic transmission, neurotransmitter recycling, and axo-dendritic transport, resulting in enhanced energy metabolism in the brain(Roh et al. 2016; Yellen 2018).

\section{Neuromodulatory responses establish brain-distant organ communication}

To support our hypothesis, we profiled a selected class of neuromodulators, neuropeptides, and neurohormones gene expression in the brain and correlated their impact on distant organs.

Corresponding to the innate physiological status, we observed a time-dependent change in the expression pattern of the respective transcripts in the brain, and other targeted tissues of mosquito such as midgut, Malpighian tubule, and ovaries. But, in turn, how these neuromodulatory responses reinforce brain action remains unknown. Recent studies in Drosophila suggest that leukokinin neuropeptide regulates protein diet-induced post-prandial sleep and minimized movement(Murphy et al. 2016). We also observed a transient increase in leukokinin, and its receptor gene in the brain, and sustained up-regulation of the leukokinin receptor gene in the gut till $30 \mathrm{~h}$ of blood-feeding. These data support the idea that until the blood meal gets digested in the gut, the brain may undergo 'food coma' and restrict external communication, but may actively engage in managing inter-organ communications (through ILPs and other neuro-hormones e.g. DH44, OEH, etc.). Compared to the brain, significant modulation of neuromodulators, and sustained expression even in the gut of decapitated blood-fed mosquitoes, further suggested a specialized ability of the gut to serve as a "second brain" possibly to share and minimize the function of the primary brain (Mayer 2011). Taken together, we interpret that gut-metabolic-switching may favor the establishment of a bidirectional 'gut-brain-axis' communication in the gravid female mosquitoes, though the detailed molecular mechanism is yet to unravel.

\section{Neurotransmitter signaling and microbiome alteration influences Gut-brain-axis communications}


Neurotransmitters, including both biogenic amines and amino acids, are well-known endogenous chemicals, that influence rapid inter-organ signal transmission and decision-making abilities(Holzer and Farzi 2014; Mittal et al. 2017). To clarify and establish a possible functional correlation between the gut metabolic switch and gut-brain axis communication, we quantified the levels of neurotransmitters secreted from both gut and brain tissues. When compared to the naïve sugar-fed status, an unusual and paramount shift from the brain to the gut was observed for almost all the neurotransmitter levels after blood feeding. A significant upregulation of aspartic acid, glutamic acid, histidine, and histamine levels in blood-fed mosquito gut and brain may be a consequence of the rapid degradation of protein-rich blood meal in the mosquito gut(Imamura et al. 1972).

Although the effect of tyrosine enrichment in the brain is intriguing, however, an undetectable level of tyrosine in the gut supports previous findings that the scavenging of toxic tyrosine from the gut is essential for the safeguarding journey of blood-fed mosquitoes(Sterkel et al. 2016). A substantial body of literature also suggests that the biogenic amines such as dopamine and serotonin are the critical regulators of feeding, host-seeking, and cognitive functions(French et al. 2014; Kamhi et al. 2017; Friedman et al. 2018; Vinauger et al. 2018; Vinauger 2019). Thus, it would be worth testing whether an increase in the precursor molecules of dopamine i.e. tyrosine, in the blood-fed mosquito's brain, improves the cognitive power of the mosquito's host-seeking and blood-feeding behavioral activities. Likewise, an enrichment of tryptophan, a precursor of serotonin, may favor the minimization of the host-seeking behavioral activities of gravid females (Fig. 5b)(Ngai et al. 2019). Additionally, 25-fold upregulation of GABAergic neurotransmission upon blood-feeding in the midgut highlights its possible function in the regulation of innate immune response by activating the autophagy due to gut flora expansion (Fig. $5 \mathrm{c}$ ) (Zhu et al. 2017; Kim et al. 2018).

Appreciably, a recent term 'psycobiotics', which aims to examine the influential effect of the microbiome on the gut-brain axis communication, is common to vertebrate's neurobiology, but insects' communities are least attended(Montiel-Castro et al. 2013; Sarkar et al. 2016). In vertebrates, studies suggested that mediators of the microbiota-gut-brain-axis communication are usually affected by microbial metabolism which includes short-chain fatty acids such as butyrate, neurotransmitters e.g. serotonin and $\mathrm{Y}$-aminobutyric acid (GABA), hormones e.g. cortisol, and other immune system modulators e.g. quinolinic acid(Parker et al. 2020). Further research on vertebrates and fruit flies indicated that gut microbiota influences several behavioral physiologies, including host metabolism, appetite, mood, sensory perception, and cognition(Gareau 2014; Kawase et al. 2017; van de Wouw et al. 2017; Westfall et al. 2018; Akami et al. 2019). Recent studies in flies also demonstrated that gut commensal bacteria and the composition of dietary amino acid supplements greatly influence in shaping behavioral responses such as food choice and olfactory guided foraging decisions(Leitão-Gonçalves et al. 2017; Wong et al. 2017; Akami et al. 2019). However, studies on mosquitoes' gut-symbionts are predominantly limited to their impact on parasite growth and their potentiality for para-transgenic approaches(Blumberg et al. 2015).

Our observation of a rapid proliferation of Pseudomonas bacterial $s p$. in the gut of blood-fed mosquitoes may likely due to increased consumption of dietary Tryptophan for the synthesis of serotonin, correlating 
a possible cause for the suppression of appetite (Fig. 6a, c \& Fig. 5c)(Jenkins et al. 2016; Kaur et al. 2019). Additionally, a significant reduction of the excitatory neurotransmitters Glutamic acid and Aspartic acid in the brain may help to restrict the foraging behavior in gravid females(Taylor and Brown 1943). However, intriguingly a parallel thousand-fold increase in aspartic acid in the gut is whether a result of gut-microbial metabolism and/or any correlation with gut-neuro-endocrine regulation for egg development remains uncertain. Previous biochemical characterization of Locust's vitellogenin protein showed that it carries high content of aspartic acid, glutamic acid, and leucine(Chen et al. 1978). An independent in-silico amino-acid composition analysis of mosquito An. culicifacies vitellogenin protein (AEO51020.1) also revealed a high content of aspartic acid (6.2\%), glutamic acid (6.7\%), phenylalanine (7.6\%), and serine (8.7\%). Furthermore, previous literature indicated that disruption of gut-microbiota by antibiotic treatment not only reduces the anti-Plasmodium immunity but also hinder the egg development in the blood-feeding mosquitoes(Gaio et al. 2011; Romoli and Gendrin 2018). Therefore, we correlate that blood-meal-induced gut-microbial metabolism and activation of the vitellogenesis process may sequester the majority of amino acids to nurture the eggs(Hansen et al. 2014). But, the remaining fraction of amino acids either serves as an energy reservoir in the fat body (Hansen et al. 2014) or functions as a neurotransmitter, possibly to maintain gut-brain-axis communication, though further studies are needed to prove these presumptions.

A noteworthy modulation of gut neurotransmitters reinforces us to test how the blood-meal induced rapid proliferation of gut flora also influence gut-brain axis communications. We disrupted the gut symbionts by providing an antibiotic diet orally supplement to the newly emerged mosquitoes for 4-5 days, and observed a significant difference in the abundance of neurotransmitters in both the gut and the brain. Surprisingly, we also noticed that aseptic adult female mosquitoes carry assertive feeding behavior towards a vertebrate host (personal observation). In animals, an earlier study showed that germ-free mice exhibited stress-induced altered behavioral response, which was restored after complete microbiota recolonization(Sudo et al. 2004). Studies further signify that the microbial antigens such as lipopolysaccharide (LPS) and lipoteichoic acids generated in response to antibiotic treatment elicit immune responses, and favors early development of the gut-brain axis communication via gut neuronal sensing (Mazzoli and Pessione 2016). In the mosquito An. stephensi, the antibiotic treatment also enhances the transcriptional responses of gut-immune peptides, but the effect on neuro-sensing remains unclarified(De et al. 2018a). We interpret that a higher abundance of histamine in the brain and GABA in the gut of antibiotic-treated mosquitoes may be accountable for the enhanced host-seeking behavioral activities, either directly through neuro-stimulation or indirectly through the vagal pathway(Bushey et al. 2015; Chen et al. 2017a). Furthermore, blood-feeding to aseptic mosquitoes resulted in a multi-fold upregulation of serine and glutamic acid suggesting a limited usage of the respective amino acids, in the lack of a microbial population (Fig. S7) (Table S4), which consumes crucial amino acids to synthesize the building blocks of bacterial cell wall components in the healthy blood-fed mosquitoes(Cava et al. 2011; Aliashkevich et al. 2018).

\section{Conclusion}


The current investigation provides a novel insight into how gut-metabolic-switch-induced transcriptional modulation shifts mosquito's brain engagement from external communication (pre-blood meal hostseeking and host selection) to manage inter-organ communication (post-blood meal physiological homeostasis) for the fitness of the mosquitoes. Although, evidences are available on the physiological effects of the gut microbiota on whole-body function in health and disease [103], but role in gut-brain-axis communication is very limited in insects. To the best of our knowledge, our data provide initial evidence that correlates the potential role of gut endosymbionts in microbiome-gut-brain-axis communication in the mosquito. We believe our conceptual framework may be valuable to modify mosquitoes' olfactory perception and cognition through the alteration of gut bacteria, and hence for new vector control tool development.

\section{Declarations}

Ethics approval and consent to participate: Not applicable

Consent for Publication: Not applicable

Funding statement: This laboratory work was supported by the Indian Council of Medical Research (ICMR), the Government of India (No.3/1/3/ICRMR-VFS/HRD/2/2016), and Tata Education and Development Trust (Health-NIMR-2017-01-03/AP/db). Tanwee Das De is the recipient of the ICMR-Post Doctoral Fellowship Scheme (3/1/3/PDF(18)/2018-HRD). Punita Sharma is the recipient of ICMRResearch Associateship award (Fellowship/52/2019-ECD-II). The funders had no role in study design, data collection, and analysis, decision to publish, or preparation of the manuscript.

Data deposition: The RNASeq sequencing data were deposited to National Centre for Biotechnology Information (NCBI) Sequence Reads Archive (SRA) system (BioProject accessions: PRJNA555826; BioSample accessions: SRR9853884 for Ac-Br-SF, SRR9853885 for Ac-Br-30Min, and SRR9853883 for AcBr-30hrs). The data could be accessed through following weblinks:

https://www.ncbi.nlm.nih.gov/sra/?term=SRR9853884

https://www.ncbi.nlm.nih.gov/sra/?term=SRR9853885

https://www.ncbi.nlm.nih.gov/sra/?term=SRR9853883

The metagenomics sequencing data were deposited to National Centre for Biotechnology Information (NCBI) Sequence Reads Archive (SRA) system include for Ac-MG-SF (SRR12579422), and for Ac-MG-BF (SRR12622557). The data could be accessed through following weblinks:

https://www.ncbi.nlm.nih.gov/sra/?term=SRR12579422

https://www.ncbi.nlm.nih.gov/sra/?term=SRR12622557 
Authors contribution statement: TDD, PS, KCP, YH, RKD: Conceived and designed the experiments: TDD, $\mathrm{PS}, \mathrm{ST}, \mathrm{DS}, \mathrm{VS}, \mathrm{CR}, \mathrm{SK}, \mathrm{ST}$, JR; RD; contributed to design and performing

the experiments, data acquisition, writing and editing; TDD, PS, YH, KCP, RKD: data analysis and interpretation, data presentation, contributed reagents/ materials/analysis tools, wrote, reviewed, edited, and finalized MS. All authors read and approved the final manuscript.

Competing interest statement: The authors declare no conflicts of interest

Acknowledgment: We thank insectary staff members for mosquito rearing. We also thank Kunwarjeet Singh for technical assistance in the laboratory. Finally, we are thankful to Xceleris Genomics, Ahmedabad, India for generating NGS sequencing data and DNAXperts, Noida, Utter Pardesh for metagenomic data generation and analysis. We thank CCAMP Metabolomics Facility for performing neurotransmitter (NT) analysis. We are grateful to Padma Ramakrishnan, Technology Scientist, Mass Spectrometry Facility - Centre for Cellular and Molecular Platforms, Bengaluru for her inputs in the manuscript by providing the details of LC/MS-based NT analysis and also thank her for troubleshooting during our study.

\section{References}

1. Aguilera G, Colín-González AL, Rangel-López E, et al (2018) Redox Signaling, Neuroinflammation, and Neurodegeneration. Antioxidants Redox Signal. https://doi.org/10.1089/ars.2017.7099

2. Akami M, Andongma AA, Zhengzhong $C$, et al (2019) Intestinal bacteria modulate the foraging behavior of the oriental fruit fly Bactrocera dorsalis (Diptera: Tephritidae). PLoS One. https://doi.org/10.1371/journal.pone.0210109

3. Aliashkevich A, Alvarez L, Cava F (2018) New insights into the mechanisms and biological roles of Damino acids in complex eco-systems. Front. Microbiol. https://doi.org/10.3389/fmicb.2018.00683

4. Arsic D, Guerin PM (2008) Nutrient content of diet affects the signaling activity of the insulin/target of rapamycin/p70 S6 kinase pathway in the African malaria mosquito Anopheles gambiae. J Insect Physiol 54:1226-1235. https://doi.org/10.1016/j.jinsphys.2008.06.003

5. Austin S, St-Pierre J (2012) PGC1 and mitochondrial metabolism - emerging concepts and relevance in ageing and neurodegenerative disorders. J Cell Sci. https://doi.org/10.1242/jcs.113662

6. Badisco L, Van Wielendaele P V., Broeck J Vanden (2013) Eat to reproduce: A key role for the insulin signaling pathway in adult insects. Front. Physiol. https://doi.org/10.3389/fphys.2013.00202

7. Beyenbach K, Petzel D (2017) Diuresis in Mosquitoes: Role of a Natriuretic Factor. Physiology. https://doi.org/10.1152/physiologyonline.1987.2.5.171

8. Beyenbach KW (2012) A dynamic paracellular pathway serves diuresis in mosquito Malpighian tubules. Ann N Y Acad Sci. https://doi.org/10.1111/j.1749-6632.2012.06527.x

9. Blumberg BJ, Short SM, Dimopoulos G (2015) Employing the Mosquito Microflora for Disease Control. In: Genetic Control of Malaria and Dengue. https://doi.org/10.1016/B978-0-12-800246- 
9.00015-6

10. Bowery NG, Smart TG (2006) GABA and glycine as neurotransmitters: A brief history. Br. J. Pharmacol. https://doi.org/10.1038/sj.bjp.0706443

11. Brown MR, Clark KD, Gulia M, et al (2008) An insulin-like peptide regulates egg maturation and metabolism in the mosquito Aedes aegypti. Proc Natl Acad Sci.

https://doi.org/10.1073/pnas.0800478105

12. Bushey D, Tononi G, Cirelli C (2015) Sleep- and wake-dependent changes in neuronal activity and reactivity demonstrated in fly neurons using in vivo calcium imaging. Proc Natl Acad Sci. https://doi.org/10.1073/pnas.1419603112

13. Castillo J, Brown MR, Strand MR (2011) Blood feeding and insulin-like peptide 3 stimulate proliferation of hemocytes in the mosquito Aedes aegypti. PLoS Pathog 7:. https://doi.org/10.1371/journal.ppat.1002274

14. Cava F, Lam H, De Pedro MA, Waldor MK (2011) Emerging knowledge of regulatory roles of d-amino acids in bacteria. Cell. Mol. Life Sci. https://doi.org/10.1007/s00018-010-0571-8

15. Chen A, Singh C, Oikonomou G, Prober DA (2017a) Genetic Analysis of Histamine Signaling in Larval Zebrafish Sleep. eneuro. https://doi.org/10.1523/eneuro.0286-16.2017

16. Chen Q, Man Y, Li J, et al (2017b) Olfactory ionotropic receptors in mosquito aedes albopictus (Diptera: Culicidae). J Med Entomol. https://doi.org/10.1093/jme/tjx063

17. Chen TT, Strahlendorf PW, Wyatt GR (1978) Vitellin and vitellogenin from locusts ( Locusta migratoria ). JBiolChem. https://doi.org/10.1016/S0021-9258(17)30373-3

18. Christ P, Reifenrath A, Kahnt J, et al (2017) Feeding-induced changes in allatostatin-A and short neuropeptide $F$ in the antennal lobes affect odor-mediated host seeking in the yellow fever mosquito, Aedes aegypti. PLoS One. https://doi.org/10.1371/journal.pone.0188243

19. Coast GM (2005) Mosquito natriuretic peptide identified as a calcitonin-like diuretic hormone in Anopheles gambiae (Giles). J Exp Biol. https://doi.org/10.1242/jeb.01760

20. Das De T, Dixit R (2020) Neuro-Olfactory Regulation and Salivary Actions: A Coordinated Event for Successful Blood-Feeding Behavior of Mosquitoes. In: Dysfunction of Olfactory System. IntechOpen, DOI: 10.5772/intechopen.90768.

21. Das De T, Hasija Y, Dixit R (2018) Transcriptional responses of attractin gene in the mosquito Anopheles culicifacies: A synergistic neuro-olfactory regulation. J Vector Borne Dis. https://doi.org/10.4103/0972-9062.242569

22. De T Das, Sharma P, Rawal C, et al (2017) Sex specific molecular responses of quick-to-court protein in Indian malarial vector Anopheles culicifacies: conflict of mating versus blood feeding behaviour. Heliyon e00361. https://doi.org/10.1016/j.heliyon.2017.e00361

23. De T Das, Sharma P, Thomas T, et al (2018a) Interorgan molecular communication strategies of "Local" and "Systemic" innate immune responses in mosquito Anopheles stephensi. Front Immunol. https://doi.org/10.3389/fimmu.2018.00148 
24. De T Das, Thomas T, Verma S, et al (2018b) A synergistic transcriptional regulation of olfactory genes drives blood-feeding associated complex behavioral responses in the mosquito anopheles culicifacies. Front Physiol. https://doi.org/10.3389/fphys.2018.00577

25. Droujinine IA, Perrimon N (2016) Interorgan Communication Pathways in Physiology: Focus on Drosophila . Annu Rev Genet. https://doi.org/10.1146/annurev-genet-121415-122024

26. Duvall LB (2019) Mosquito Host-Seeking Regulation: Targets for Behavioral Control. Trends Parasitol. https://doi.org/10.1016/j.pt.2019.06.010

27. Duvall LB, Ramos-Espiritu L, Barsoum KE, et al (2019) Small-Molecule Agonists of Ae. aegypti Neuropeptide Y Receptor Block Mosquito Biting. Cell. https://doi.org/10.1016/j.cell.2018.12.004

28. Fadda M, Hasakiogullari I, Temmerman L, et al (2019) Regulation of Feeding and Metabolism by Neuropeptide F and Short Neuropeptide F in Invertebrates. Front Endocrinol (Lausanne). https://doi.org/10.3389/fendo.2019.00064

29. Forsythe P, Kunze WA (2013) Voices from within: Gut microbes and the CNS. Cell. Mol. Life Sci. https://doi.org/10.1007/s00018-012-1028-z

30. French AS, Simcock KL, Rolke D, et al (2014) The role of serotonin in feeding and gut contractions in the honeybee. J Insect Physiol 61:8-15. https://doi.org/10.1016/j.jinsphys.2013.12.005

31. Friedman DA, Pilko A, Skowronska-Krawczyk D, et al (2018) The Role of Dopamine in the Collective Regulation of Foraging in Harvester Ants. Food Sci Hum Wellness. https://doi.org/10.1016/j.isci.2018.09.001

32. Fülling C, Dinan TG, Cryan JF (2019) Gut Microbe to Brain Signaling: What Happens in Vagus.... Neuron. https://doi.org/10.1016/j.neuron.2019.02.008

33. Gaio ADO, Gusmão DS, Santos A V., et al (2011) Contribution of midgut bacteria to blood digestion and egg production in aedes aegypti (diptera: Culicidae) (L.). Parasites and Vectors. https://doi.org/10.1186/1756-3305-4-105

34. Gareau MG (2014) Microbiota-gut-brain axis and cognitive function. Adv Exp Med Biol. https://doi.org/10.1007/978-1-4939-0897-4_16

35. Guégan M, Zouache K, Démichel C, et al (2018) The mosquito holobiont: fresh insight into mosquitomicrobiota interactions. Microbiome. https://doi.org/10.1186/s40168-018-0435-2

36. Gulia-Nuss M, Robertson AE, Brown MR, Strand MR (2011) Insulin-like peptides and the target of rapamycin pathway coordinately regulate blood digestion and egg maturation in the mosquito Aedes aegypti. PLoS One. https://doi.org/10.1371/journal.pone.0020401

37. Hansen IA, Attardo GM, Rodriguez SD, Drake LL (2014) Four-way regulation of mosquito yolk protein precursor genes by juvenile hormone-, ecdysone-, nutrient-, and insulin-like peptide signaling pathways. Front. Physiol. https://doi.org/10.3389/fphys.2014.00103

38. Holzer P, Farzi A (2014) Neuropeptides and the microbiota- Gut-brain axis. Adv Exp Med Biol. https://doi.org/10.1007/978-1-4939-0897-4_9 
39. Hou Y, Wang XL, Saha TT, et al (2015) Temporal Coordination of Carbohydrate Metabolism during Mosquito Reproduction. PLoS Genet. https://doi.org/10.1371/journal.pgen.1005309

40. Huson DH, Auch AF, Qi J, Schuster SC (2007) MEGAN analysis of metagenomic data. Genome Res. https://doi.org/10.1101/gr.5969107

41. Imamura T, Baldwin TO, Riggs A (1972) The amino acid sequence of the monomeric hemoglobin component from the bloodworm, Glyat liver. J Biol Chem. https://doi.org/10.1016/S00219258(19)45280-0

42. Jenkins TA, Nguyen JCD, Polglaze KE, Bertrand PP (2016) Influence of tryptophan and serotonin on mood and cognition with a possible role of the gut-brain axis. Nutrients

43. Kamhi JF, Arganda S, Moreau CS, Traniello JFA (2017) Origins of Aminergic Regulation of Behavior in Complex Insect Social Systems. Front Syst Neurosci 11:. https://doi.org/10.3389/fnsys.2017.00074

44. Kaur H, Bose C, Mande SS (2019) Tryptophan Metabolism by Gut Microbiome and Gut-Brain-Axis: An in silico Analysis. Front Neurosci. https://doi.org/10.3389/fnins.2019.01365

45. Kawase $T$, Nagasawa $M$, Ikeda $H$, et al (2017) Gut microbiota of mice putatively modifies amino acid metabolism in the host brain. Br J Nutr. https://doi.org/10.1017/S0007114517000678

46. Kersch CN, Pietrantonio P V. (2011) Mosquito Aedes aegypti (L.) leucokinin receptor is critical for in vivo fluid excretion post blood feeding. FEBS Lett. https://doi.org/10.1016/j.febslet.2011.10.001

47. Kim JK, Kim YS, Lee HM, et al (2018) GABAergic signaling linked to autophagy enhances host protection against intracellular bacterial infections. Nat Commun. https://doi.org/10.1038/s41467018-06487-5

48. Kinney MP, Panting ND, Clark TM (2014) Modulation of appetite and feeding behavior of the larval mosquito Aedes aegypti by the serotonin-selective reuptake inhibitor paroxetine: shifts between distinct feeding modes and the influence of feeding status. J Exp Biol. https://doi.org/10.1242/jeb.094904

49. Kuczynski J, Stombaugh J, Walters WA, et al (2011) Using QIIME to analyze 16S rna gene sequences from microbial communities. Curr Protoc Bioinforma. https://doi.org/10.1002/0471250953.bi1007s36

50. Lampe L, Jentzsch M, Kierszniowska S, Levashina EA (2019) Metabolic balancing by miR-276 shapes the mosquito reproductive cycle and Plasmodium falciparum development. Nat Commun. https://doi.org/10.1038/s41467-019-13627-y

51. Leitão-Gonçalves R, Carvalho-Santos Z, Francisco AP, et al (2017) Commensal bacteria and essential amino acids control food choice behavior and reproduction. PLoS Biol. https://doi.org/10.1371/journal.pbio.2000862

52. Liang H, Ward WF (2006) PGC-1a: a key regulator of energy metabolism. Adv Physiol Educ. https://doi.org/10.1152/advan.00052.2006

53. Liesch J, Bellani LL, Vosshall LB (2013) Functional and Genetic Characterization of Neuropeptide YLike Receptors in Aedes aegypti. PLoS Negl Trop Dis 7:. 
https://doi.org/10.1371/journal.pntd.0002486

54. Lin J, Handschin C, Spiegelman BM (2005) Metabolic control through the PGC-1 family of transcription coactivators. Cell Metab. https://doi.org/10.1016/j.cmet.2005.05.004

55. Ling L, Raikhel AS (2018) Serotonin signaling regulates insulin-like peptides for growth, reproduction, and metabolism in the disease vector Aedes aegypti . Proc Natl Acad Sci. https://doi.org/10.1073/pnas.1808243115

56. Liu Q, Jin LH (2017) Organ-to-Organ Communication: A Drosophila Gastrointestinal Tract Perspective. Front Cell Dev Biol. https://doi.org/10.3389/fcell.2017.00029

57. Livak KJ, Schmittgen TD (2001) Analysis of relative gene expression data using real-time quantitative PCR and the 2(-Delta Delta C(T)) Method. Methods 25:402-8. https://doi.org/10.1006/meth.2001.1262

58. Matthews BJ, McBride CS, DeGennaro M, et al (2016) The neurotranscriptome of the Aedes aegypti mosquito. BMC Genomics. https://doi.org/10.1186/s12864-015-2239-0

59. Mattila J, Hietakangas V (2017) Regulation of carbohydrate energy metabolism in Drosophila melanogaster. Genetics. https://doi.org/10.1534/genetics.117.199885

60. Mayer EA (2011) Gut feelings: The emerging biology of gut-"brain communication. Nat. Rev. Neurosci. https://doi.org/10.1038/nrn3071

61. Mazzoli R, Pessione E (2016) The neuro-endocrinological role of microbial glutamate and GABA signaling. Front. Microbiol. https://doi.org/10.3389/fmicb.2016.01934

62. Mittal R, Debs LH, Patel AP, et al (2017) Neurotransmitters: The Critical Modulators Regulating GutBrain Axis. J. Cell. Physiol. https://doi.org/10.1002/jcp.25518

63. Montiel-Castro AJ, González-Cervantes RM, Bravo-Ruiseco G, Pacheco-López G (2013) The microbiota-gut-brain axis: neurobehavioral correlates, health and sociality. Front Integr Neurosci. https://doi.org/10.3389/fnint.2013.00070

64. Murphy KR, Deshpande SA, Yurgel ME, et al (2016) Postprandial sleep mechanics in Drosophila. Elife. https://doi.org/10.7554/eLife.19334

65. Natarajan N, Ramakrishnan P, Lakshmanan V, et al (2015) A quantitative metabolomics peek into planarian regeneration. Analyst. https://doi.org/10.1039/c4an02037e

66. Ngai M, Shoue DA, Loh Z, McDowell MA (2019) The pharmacological and functional characterization of the serotonergic system in Anopheles gambiae and Aedes aegypti: influences on flight and blood-feeding behavior. Sci Rep. https://doi.org/10.1038/s41598-019-38806-1

67. O'Mahony SM, Clarke G, Borre YE, et al (2015) Serotonin, tryptophan metabolism and the brain-gutmicrobiome axis. Behav. Brain Res. https://doi.org/10.1016/j.bbr.2014.07.027

68. Omondi AB, Ghaninia M, Dawit M, et al (2019) Age-dependent regulation of host seeking in Anopheles coluzzii. Sci Rep. https://doi.org/10.1038/s41598-019-46220-w

69. Oriach CS, Robertson RC, Stanton C, et al (2016) Food for thought: The role of nutrition in the microbiota-gut-brain axis. Clin. Nutr. Exp. https://doi.org/10.1016/j.yclnex.2016.01.003 
70. Parker A, Fonseca S, Carding SR (2020) Gut microbes and metabolites as modulators of blood-brain barrier integrity and brain health. Gut Microbes. https://doi.org/10.1080/19490976.2019.1638722

71. Piermarini PM, Esquivel CJ, Denton JS (2017) Malpighian tubules as novel targets for mosquito control. Int. J. Environ. Res. Public Health. https://doi.org/10.3390/ijerph14020111

72. Plaçais PY, De Tredern É, Scheunemann L, et al (2017) Upregulated energy metabolism in the Drosophila mushroom body is the trigger for long-term memory. Nat Commun. https://doi.org/10.1038/ncomms 15510

73. Potter CJ (2014) Stop the biting: Targeting a mosquito's sense of smell. Cell 156:878-881. https://doi.org/10.1016/j.cell.2014.02.003

74. Ramesh D, Brockmann A (2019) Mass Spectrometric Quantification of Arousal Associated Neurochemical Changes in Single Honey Bee Brains and Brain Regions. ACS Chem Neurosci. https://doi.org/10.1021/acschemneuro.8b00254

75. Ridaura V, Belkaid Y (2015) Gut microbiota: The link to your second brain. Cell. https://doi.org/10.1016/j.cell.2015.03.033

76. Roh E, Song DK, Kim MS (2016) Emerging role of the brain in the homeostatic regulation of energy and glucose metabolism. Exp. Mol. Med. https://doi.org/10.1038/emm.2016.4

77. Romoli O, Gendrin M (2018) The tripartite interactions between the mosquito, its microbiota and Plasmodium. Parasites and Vectors. https://doi.org/10.1186/s13071-018-2784-x

78. Sanders HR, Evans AM, Ross LS, Gill SS (2003) Blood meal induces global changes in midgut gene expression in the disease vector, Aedes aegypti. Insect Biochem Mol Biol 33:1105-1122. https://doi.org/10.1016/S0965-1748(03)00124-3

79. Sarkar A, Lehto SM, Harty S, et al (2016) Psychobiotics and the Manipulation of Bacteria-Gut-Brain Signals. Trends Neurosci. https://doi.org/10.1016/j.tins.2016.09.002

80. Sharma A, Nuss AB, Gulia-Nuss M (2019) Insulin-like peptide signaling in mosquitoes: The road behind and the road ahead. Front. Endocrinol. (Lausanne). https://doi.org/10.3389/fendo.2019.00166

81. Sharma P, Rani J, Chauhan C, et al (2020) Altered Gut Microbiota and Immunity Defines Plasmodium vivax Survival in Anopheles stephensi. Front Immunol. https://doi.org/10.3389/fimmu.2020.00609

82. Sharma P, Sharma S, Mishra AK, et al (2015) Unraveling dual feeding associated molecular complexity of salivary glands in the mosquito Anopheles culicifacies. Biol Open 4:1002-15. https://doi.org/10.1242/bio.012294

83. Shukla E, Thorat LJ, Nath BB, Gaikwad SM (2015) Insect trehalase: Physiological significance and potential applications. Glycobiology. https://doi.org/10.1093/glycob/cwu125

84. Sim C, Denlinger DL (2009) A shut-down in expression of an insulin-like peptide, ILP-1, halts ovarian maturation during the overwintering diapause of the mosquito Culex pipiens. Insect Mol Biol. https://doi.org/10.1111/j.1365-2583.2009.00872.x 
85. Solari P, Rivelli N, De Rose F, et al (2017) Opposite effects of 5-HT/AKH and octopamine on the crop contractions in adult Drosophila melanogaster: Evidence of a double brain-gut serotonergic circuitry. PLoS One. https://doi.org/10.1371/journal.pone.0174172

86. Sterkel M, Perdomo HD, Guizzo MG, et al (2016) Tyrosine Detoxification Is an Essential Trait in the Life History of Blood-Feeding Arthropods. Curr Biol. https://doi.org/10.1016/j.cub.2016.06.025

87. Strand MR, Brown MR, Vogel KJ (2016) Mosquito Peptide Hormones: Diversity, Production, and Function. In: Advances in Insect Physiology. https://doi.org/10.1016/bs.aiip.2016.05.003

88. Sudo N, Chida Y, Aiba Y, et al (2004) Postnatal microbial colonization programs the hypothalamicpituitary-adrenal system for stress response in mice. J Physiol. https://doi.org/10.1113/jphysiol.2004.063388

89. Takken W, Van Loon JJA, Adam W (2001) Inhibition of host-seeking response and olfactory responsiveness in Anopheles gambiae following blood feeding. J Insect Physiol 47:303-310. https://doi.org/10.1016/S0022-1910(00)00107-4

90. Tallon AK, Hill SR, Ignell R (2019) Sex and age modulate antennal chemosensory-related genes linked to the onset of host seeking in the yellow-fever mosquito, Aedes aegypti. Sci Rep. https://doi.org/10.1038/s41598-018-36550-6

91. Taylor P, Brown JH (1943) Basic Neurochemistry: Molecular, Cellular and Medical Aspects . 6th edition .

92. van de Wouw M, Schellekens H, Dinan TG, Cryan JF (2017) Microbiota-Gut-Brain Axis: Modulator of Host Metabolism and Appetite. J Nutr. https://doi.org/10.3945/jn.116.240481

93. Vinauger $C$ (2019) Vector cognition and neurobiology. Curr. Opin. Insect Sci. https://doi.org/10.1016/j.cois.2019.04.002

94. Vinauger C, Lahondère C, Wolff GH, et al (2018) Modulation of Host Learning in Aedes aegypti Mosquitoes. Curr Biol. https://doi.org/10.1016/j.cub.2017.12.015

95. Vogel KJ, Brown MR, Strand MR (2015) Ovary ecdysteroidogenic hormone requires a receptor tyrosine kinase to activate egg formation in the mosquito Aedes aegypti . Proc Natl Acad Sci. https://doi.org/10.1073/pnas.1501814112

96. Volkenhoff A, Weiler A, Letzel M, et al (2015) Glial glycolysis is essential for neuronal survival in drosophila. Cell Metab. https://doi.org/10.1016/j.cmet.2015.07.006

97. Westfall S, Lomis N, Prakash S (2018) Longevity extension in Drosophila through gut-brain communication. Sci Rep. https://doi.org/10.1038/s41598-018-25382-z

98. Wong ACN, Wang QP, Morimoto J, et al (2017) Gut Microbiota Modifies Olfactory-Guided Microbial Preferences and Foraging Decisions in Drosophila. Curr Biol. https://doi.org/10.1016/j.cub.2017.07.022

99. Yellen G (2018) Fueling thought: Management of glycolysis and oxidative phosphorylation in neuronal metabolism. J. Cell Biol. https://doi.org/10.1083/jcb.201803152 
100. Zhang Q, Denlinger DL (2011) Molecular structure of the prothoracicotropic hormone gene in the northern house mosquito, Culex pipiens, and its expression analysis in association with diapause and blood feeding. Insect Mol Biol. https://doi.org/10.1111/j.1365-2583.2010.01058.x

101. Zhu Y, Zhang R, Zhang B, et al (2017) Blood meal acquisition enhances arbovirus replication in mosquitoes through activation of the GABAergic system. Nat Commun.

https://doi.org/10.1038/s41467-017-01244-6

102. (1999) The Role of Protein and Amino Acids in Sustaining and Enhancing Performance. National Academies Press (US); 1999. ISBN-10: 0-309-06346-9

\section{Figures}

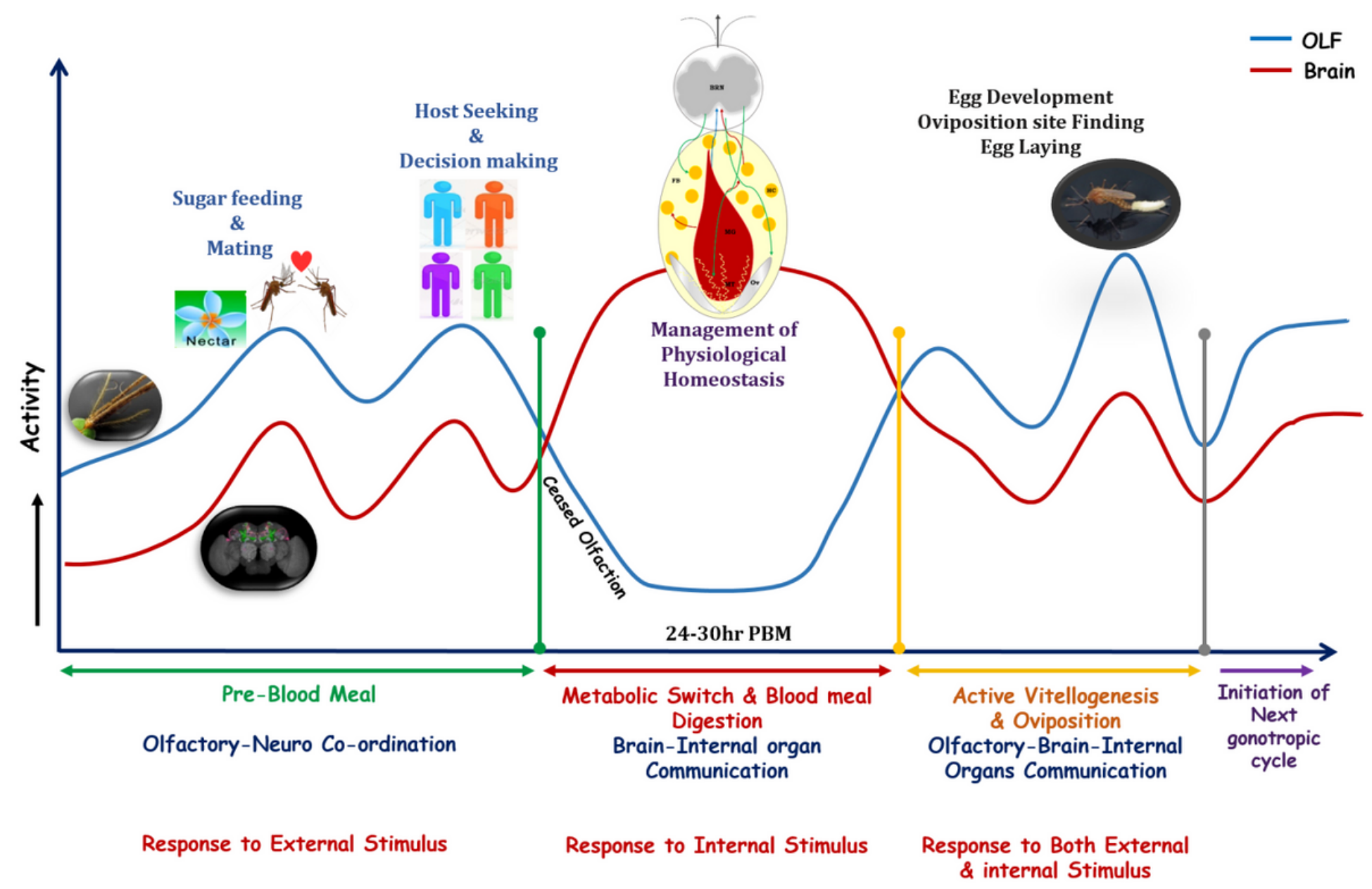

Figure 1

A proposed working hypothesis to establish the correlation between the gut metabolic switch and brain functions in adult female mosquitoes. The behavior of any organism is a very complex event that needs tight coordination between the sensory and neuronal systems. After emergence from pupae, the dynamic changes in the neuro-olfactory system coordinate and regulate different behavioral activities such as mating, sugar feeding, and vertebrate host-seeking, etc. These pre-blood meal-associated behaviors are guided by external stimuli, followed by neuronal decision making. Once the female mosquitoes take a 
blood meal, their olfactory responses are temporarily arrested to minimize brain and environmental (external) communication. But blood-feeding causes a global change in the physiological homeostasis, and drives multiple tissues (midgut, Malpighian tubule, ovary, and fat body) engagement to manage the systemic equilibrium. Here, we hypothesize that an 'internal stimulus' of gut-metabolic-switch may modulate brain functions to ensure optimal inter-organ communication, at least for the first $30 \mathrm{~h}$ until blood meal digestion is completed in the gut. However, after 30-40h of blood-feeding reactivation of the olfactory system, restores olfactory-neuro co-ordination to perform the next level of behavioral activities, such as oviposition and initiation of the second gonotrophic cycle. Blue and red lines indicate the possible functional patterns of the olfactory system (OLF) and the brain, respectively. 
(a)
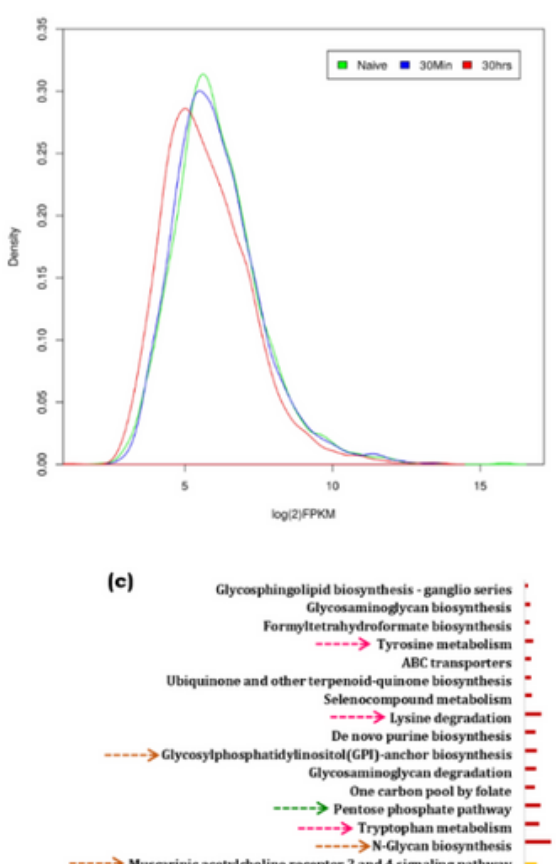

$\rightarrow-\rightarrow$ Muscarinic acetyldoline receptor 2 and 4 signaling pattiway

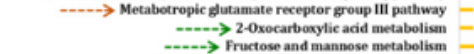

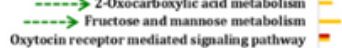

Oxy tocin receptor mediated siggaling pathway
Fatry acid elongation

$\rightarrow-\rightarrow$ Beta2 adrenergie mecptor signaling patiway

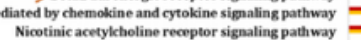

Nicotimic acetylcholine recoptor signaling pattway
Aminoscy-trRA biosynthesis

in endoplasmic reticulum

Replicatioe and repais

Phototranstuction - ny

sect Hormene Biosynthesis

Regulation of autophagy

Co-Enzyme Symthesis $\overline{\text { 三 }}$

Nuchootide metabolism

Signaling Pathway
Lid metabolis

Lysosome
Amino acid metabolism

Purine metabolism

Endocytesis
Peroxisom

Transcription and Translatio
Ubiquitin mediated proteoly

mediated proteolysis

$\overline{\bar{\equiv}}$

$\overline{\overline{\bar{Z}}}$

$\overline{\bar{\equiv}}$

$\overline{\bar{\equiv}}$

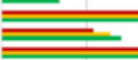
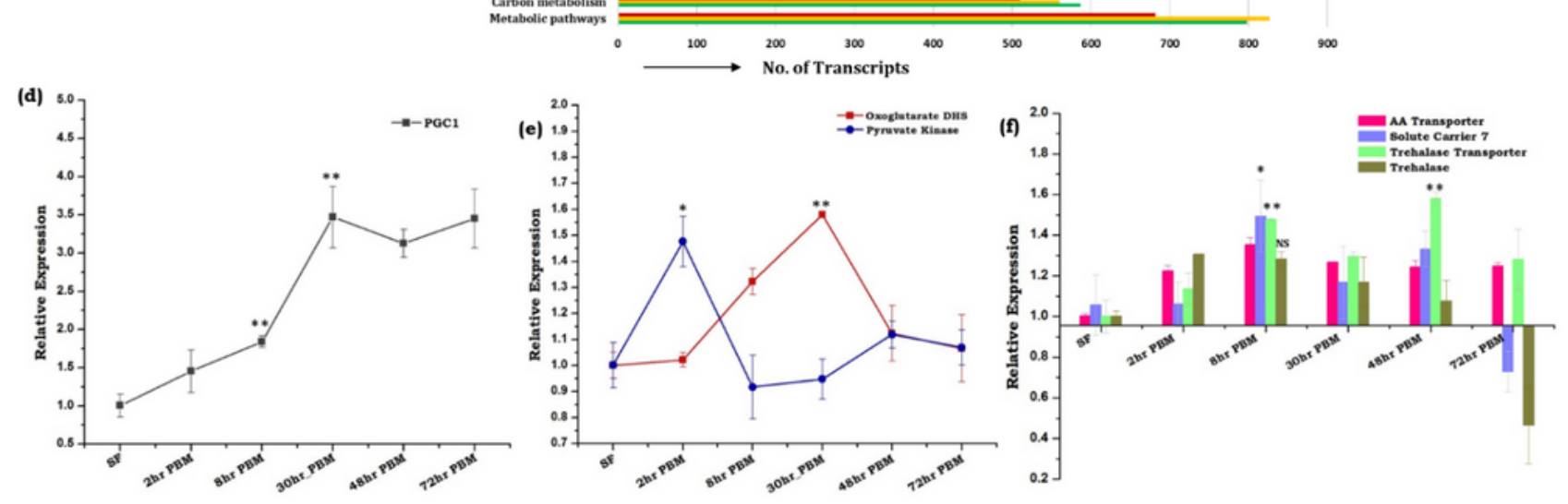

\section{Figure 2}

Blood meal causes notable changes in the molecular architecture of the brain tissue. (a) Comparison of the read density map of the naïve, $30 \mathrm{~min}$, and $30 \mathrm{~h}$ post blood meal (PBM) transcriptomic data of brain tissue ( $n=25)$; (b) Functional annotation and molecular cataloging of brain transcriptome (Biological Process/Level4/Node score). Purple circle highlighted the unique category of genes that appeared in the brain tissue after blood meal intake; (c) KOBAS 3.0 software mediated gene list enrichment and 
comparative pathway analysis of naïve and blood-fed brain tissues. Green arrow links to energy metabolic pathways, the pink arrow links to neurotransmitter synthesis pathway, and the brown arrow indicate neurite out-growth and synaptic transmission; (d) Relative expression profiling of PGC-1 gene in the brain of naïve and blood-fed mosquitoes $(n=25, N=3)$; (e) Transcriptional profiling of transcripts related to energy metabolism in the brain tissue of naïve and blood-fed mosquitoes at different time points; (f) Comparative transcriptional response of amino acid transporters and trehalose transporter along with trehalase enzyme in the brain tissue after the metabolic switch $(n=25, N=3)$. Statistically significant variation in the expression of the respective genes was tested by the t-test and compared with the sugar-fed control brain. $(n=$ number of mosquitoes from, which the respective tissue was dissected and pooled for each independent experiment; $\mathrm{N}=$ number of biological replicates). $\mathrm{SF}$ = naïve sugar-fed, 2hr-PBM (Post-Blood-Meal); 8hr-PBM; 30hr-PBM; 48hr-PBM; 72hr-PBM.

(a)

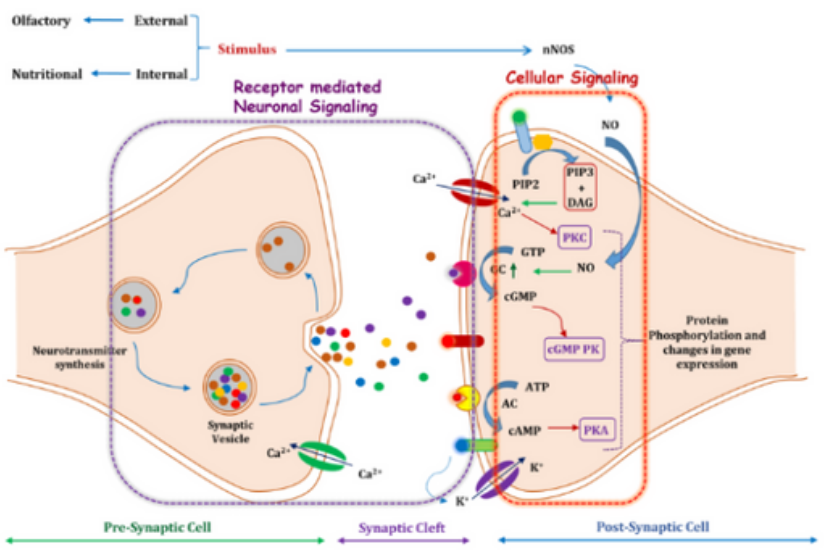

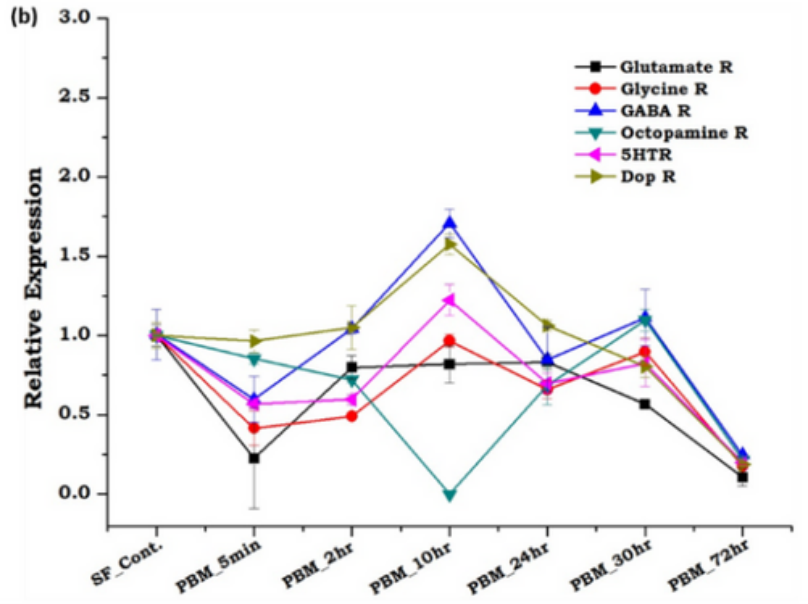
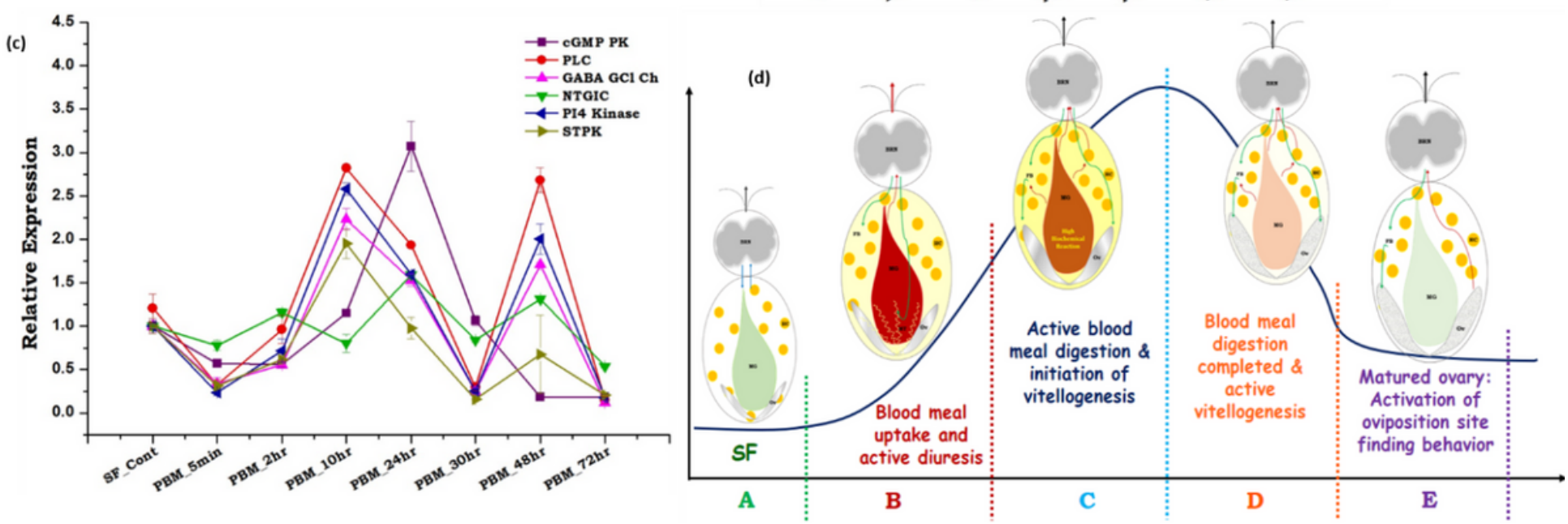

Figure 3

Metabolic switch influences neuro-signaling modulation and inter-organ communication. (a) Synaptic signal transmission and probable mechanism of neuro-signaling. After activation by external and/or internal stimuli, the synaptic vesicles of the presynaptic neuron, containing the neurotransmitters, are released into the synaptic cleft. Binding of the respective neurotransmitter with their cognate receptors activates the downstream signal transduction process in the postsynaptic neuron and thus activates and transmits the initial signal through the interconnecting neurons; (b) Transcriptional response of 
neurotransmitter receptor genes as per the designed blood meal time-series experiment. Brain tissues were collected from 5-6day old naïve sugar-fed adult female mosquitoes. Then, mosquitoes were provided with blood meal, and the brain tissues were collected at different time points after blood feeding viz. 5min post blood meal (PBM-5min), PBM-2h, PBM-10h, PBM-24h, PBM 30h, and PBM-72h. Glutamate R: Glutamate Receptor; Glycine R: Glycine Receptor; GABA R: Gamma-Aminobutyric Acid Receptor; Octopamine R: Octopamine Receptor; 5HTR: Serotonin Receptor; Dop R: Dopamine Receptor. Statistical analysis using two-way ANOVA has implied at 0.05 level the expression pattern of the respective genes was not statistically significant at $p \leq 0.2$ at different time points after blood feeding $(n=25, N=4)$; (c) Relative expression profiling of the genes involved in signal transduction molecules according to the detailed blood meal time-series experiment. cGMP PK: Cyclic GMP Protein Kinase; PLC: Phospholipase C; GABA GCICh: GABA Gated Chloride Channel; NTGIC: Neurotransmitter Gated Ion Channel; PI4 Kinase: Phosphatidyl-inositol-4-Kinase; STPK: Serine Threonine Protein Kinase. Statistical analysis using two-way ANOVA stated that the expression change of the respective genes is statistically significant $p \leq 0.005(n=$ $25, N=4$ ); (d) Schematic representation of the brain's possible engagement during inter-organ communication after the gut-metabolic switch. Brain actions are subdivided into different phases. We proposed, while in sugar-fed status, the brain manages daily behavioral activities, but as soon as mosquitoes take blood-meal, rapid modulation of the brain's intracellular signaling occurs to manage multiple physiological events such as diuresis process for osmotic regulation, active blood meal digestion in the midgut, co-ordinate with MG, FB, and ovary for egg maturation and vitellogenesis. After 30-40h of blood-feeding, brain function restores to coordinate the reactivated olfactory system. ( $\mathrm{n}=$ number of mosquitoes from which the respective tissue was dissected and pooled for each independent experiment; $\mathrm{N}$ = number of biological replicates)
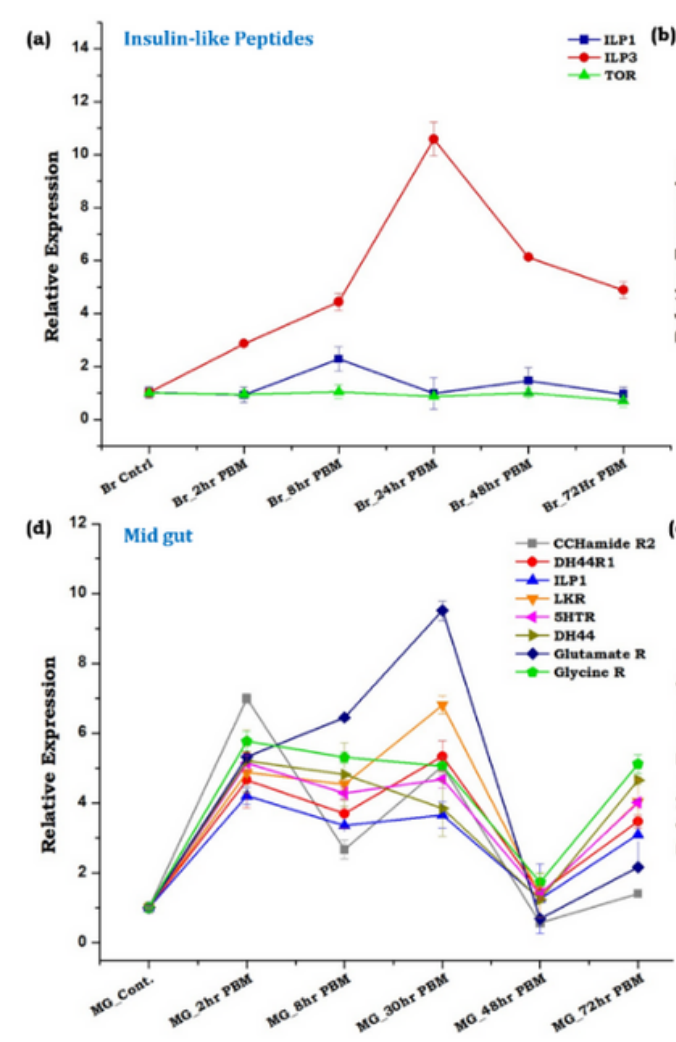
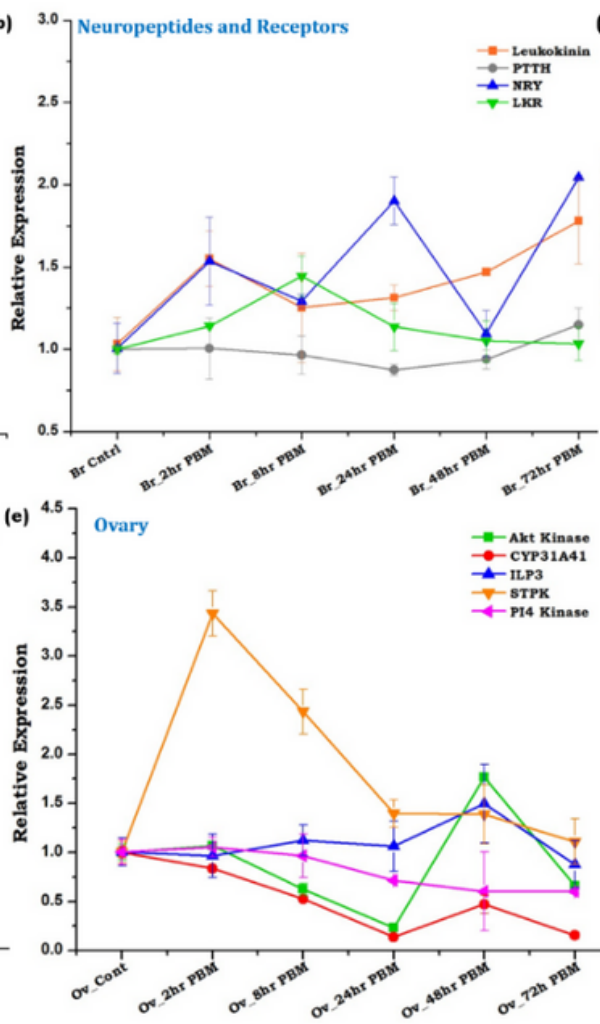
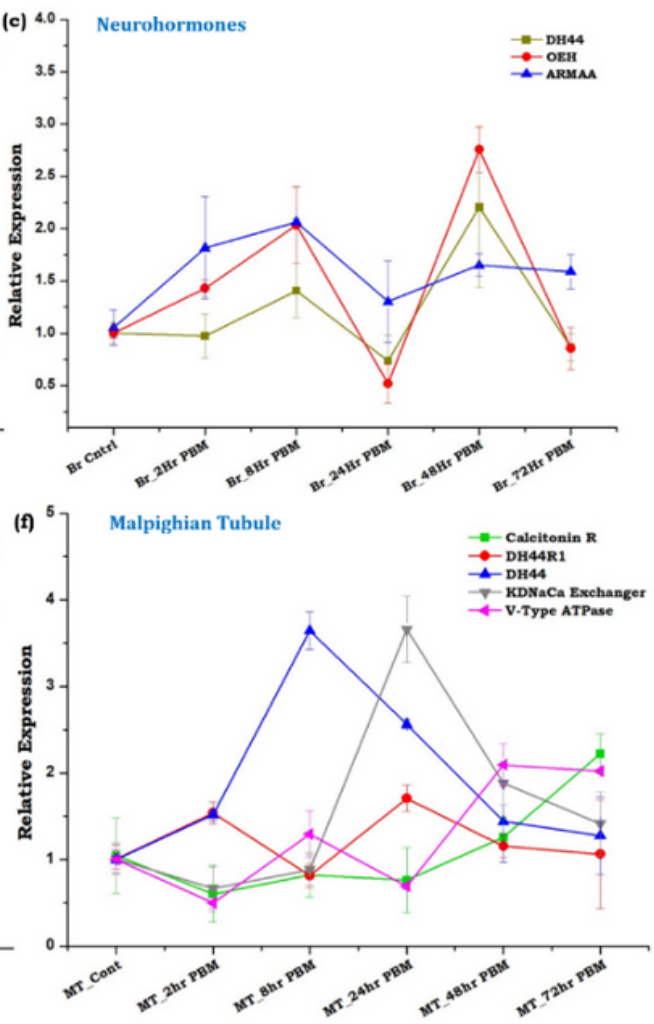


\section{Figure 4}

Metabolic switch modulates tissue-specific neuro-modulator transcripts expression. (a-c) Transcriptional expression profiling of Insulin-like-peptides, neuropeptides, neurohormones, and receptor genes in the brain tissue during the metabolic switch. Statistical analysis using two-way ANOVA and Tukey's test implied that the expression change of the respective genes is statistically significant for insulin-likepeptides $p \leq 0.007$; neuropeptides and receptors $p \leq 0.009$, but for neuro-hormones, it was nonsignificant $p \leq 0.2(n=25, N=4)$; (d) Relative expression profiling of a subset of neuromodulator genes in the midgut of naïve and blood-fed mosquitoes at the same time point described above. Statistical analysis using two-way ANOVA implied that the expression change of the respective genes is statistically significant $p \leq 0.005(n=12, N=4)$; (e) Transcriptional profiling of genes involved in signal transduction during vitellogenesis in the ovary. Statistical analysis using two-way ANOVA and Tukey's test indicated that the expression change of the respective genes was statistically significant at $p \leq 0.002(n=12, N=$ 4); (f) Relative gene expression analysis of diuresis-related genes in the Malpighian tubule of naïve and blood-fed mosquitoes. Statistical analysis using two-way ANOVA and Tukey's test indicates that the expression change of the respective genes is non-significant at $p \leq 0.4(n=25, N=4)$. ( $n=$ number of mosquitoes from which the respective tissue was dissected and pooled for each independent experiment; $\mathrm{N}=$ number of biological replicates) 


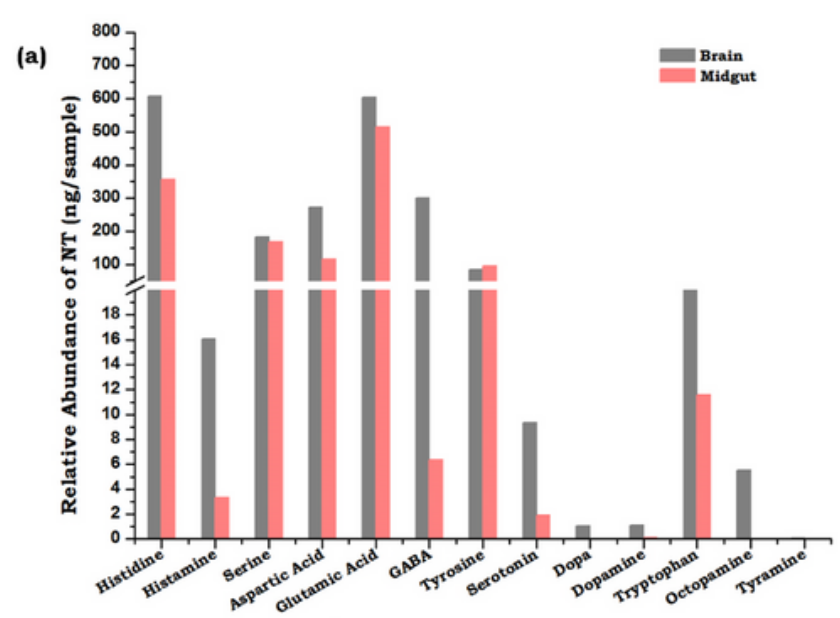

(b)

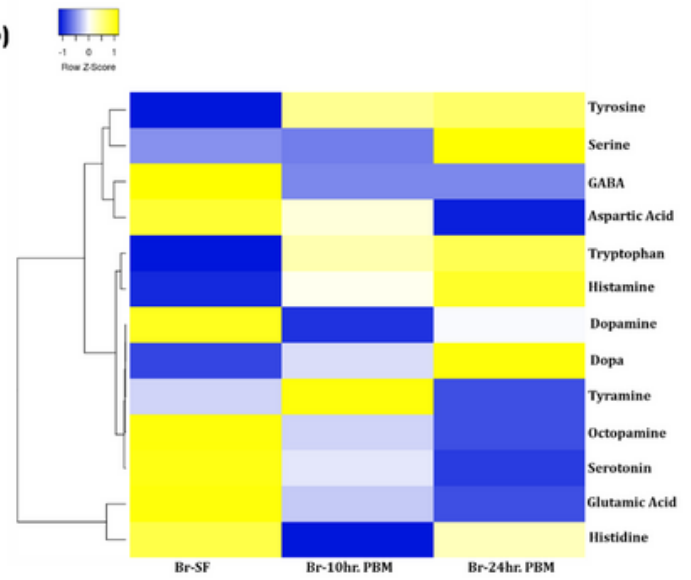

(d)
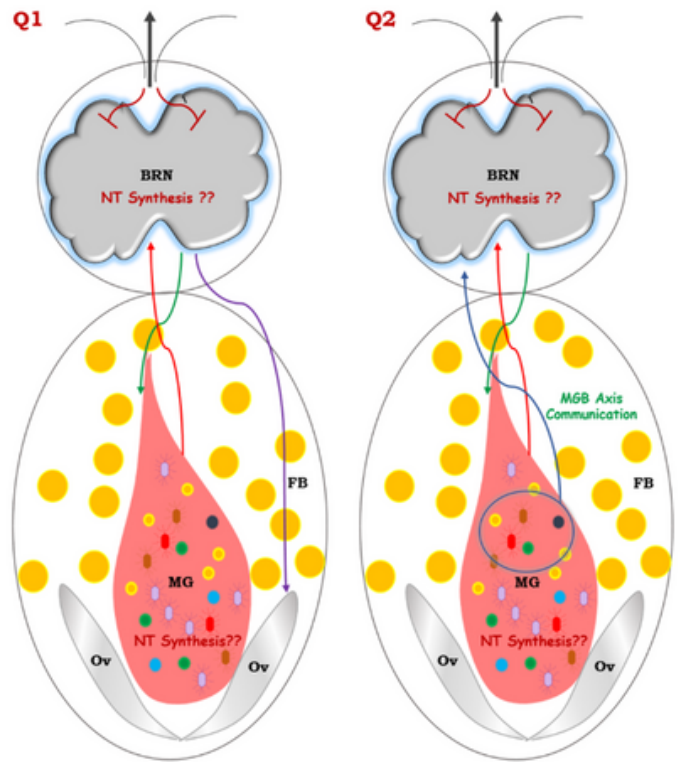

(c)
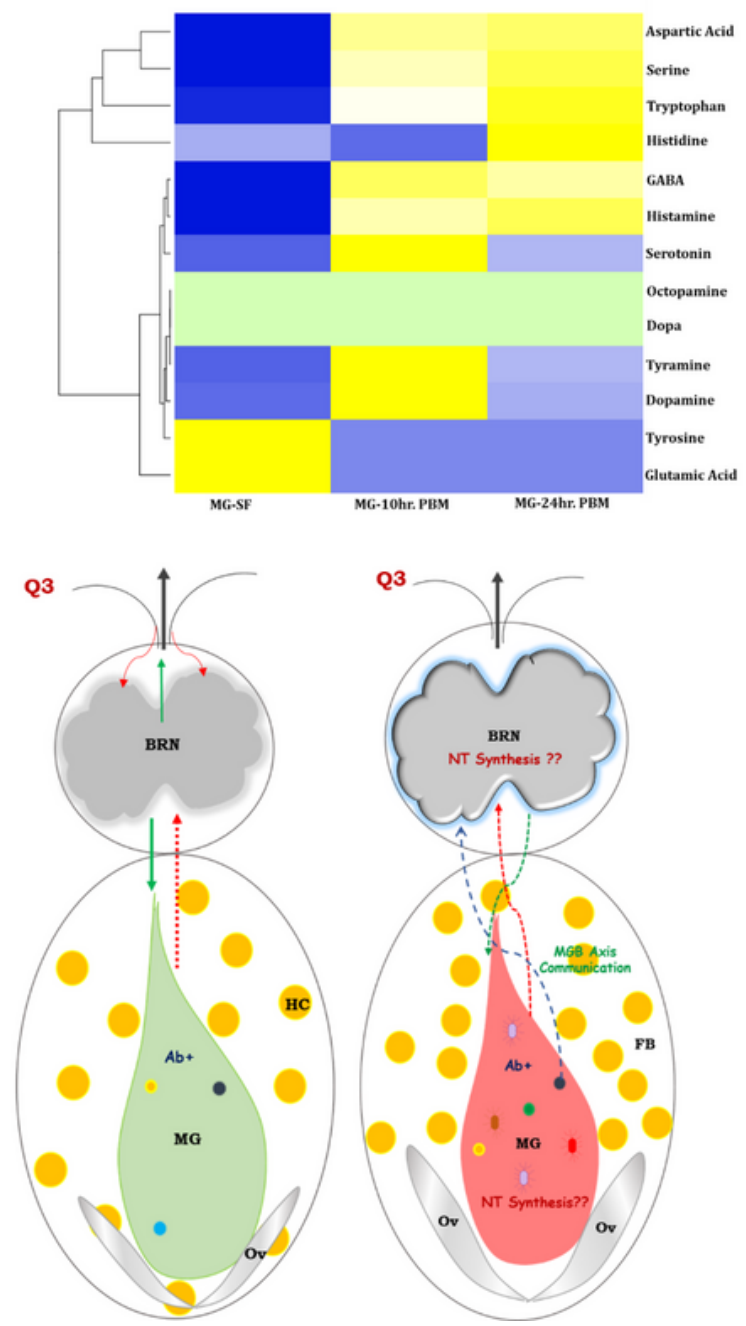

Figure 5

Gut-Brain-Axis (GBA) communication and neurotransmitter (NT) estimation in mosquito An. culicifacies.

(a) Comparative analysis of NT abundance in the naïve mosquitoes' brain and midgut; (b) Heatmap showing the alteration of neurotransmitters level in mosquito brain tissue. NT levels were measured by LC-MS from the brains of naïve (sugar-fed) and blood-fed females (10 and $24 \mathrm{~h}$ PBM) $(n=65, N=2)$. Statistically significant differences in the amount of metabolites were tested by $p$-values $(p \leq 0.005)$ that 
are deduced by two-way ANOVA and Tukey's test; (c) Heatmap of neurotransmitters levels of mosquito gut tissue that vary during the metabolic switch. NT levels were measured by LC-MS from the gut of naïve (sugar-fed) and blood-fed females (10 and $24 \mathrm{~h}$ PBM) $(n=50, N=2)$. Statistically significant differences in the amount of metabolites were tested by $p$-values $(p \leq 0.005)$ that are deduced by two-way ANOVA and Tukey's test. ( $n=$ number of mosquitoes from which the respective tissue was dissected and pooled for each independent experiment; $\mathrm{N}=$ number of biological replicates); (d) Pictorial presentation demonstrating GBA communication in response to gut-metabolic switch in mosquitoes. Q1: Bloodfeeding pauses external stimulus-guided neuro-olfactory responses, but may shift brain engagement through the vagus pathway (red arrow) to regulate actions in the distant organs such as the midgut (green arrow) and ovary (purple arrow). Here, we questioned whether increased levels of amino acids in the gut during blood meal digestion may act like an NT. Q2: Do blood-meal-induced gut flora proliferation (different colored shapes indicate diverse microbial flora) influence GBA communication in mosquitoes. Q3: Whether gut-bacterial removal by antibiotic treatment confers the establishment of microbiome-gutbrain axis (MGB) communication. BRN: Brain, MG: midgut, FB: Fat body, Ov: Ovary, Ab+: Antibiotic positive/treated. 
(a)

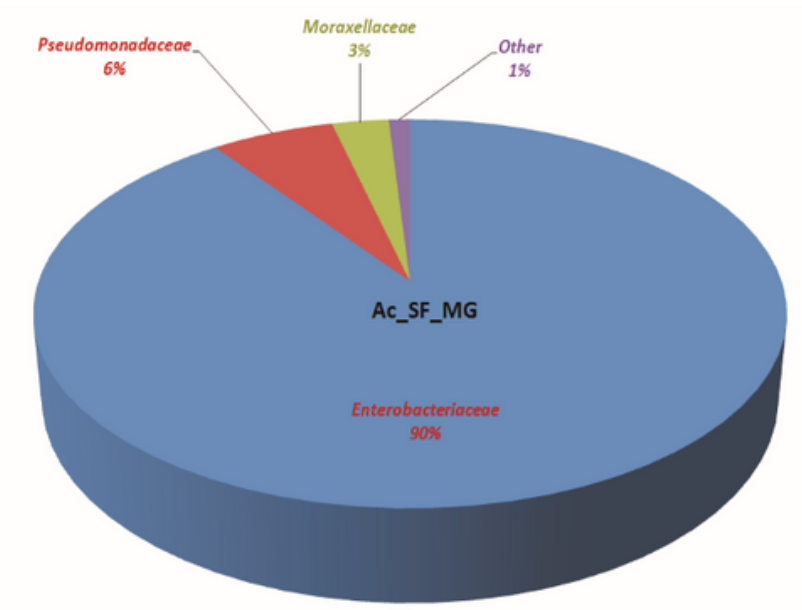

(b)

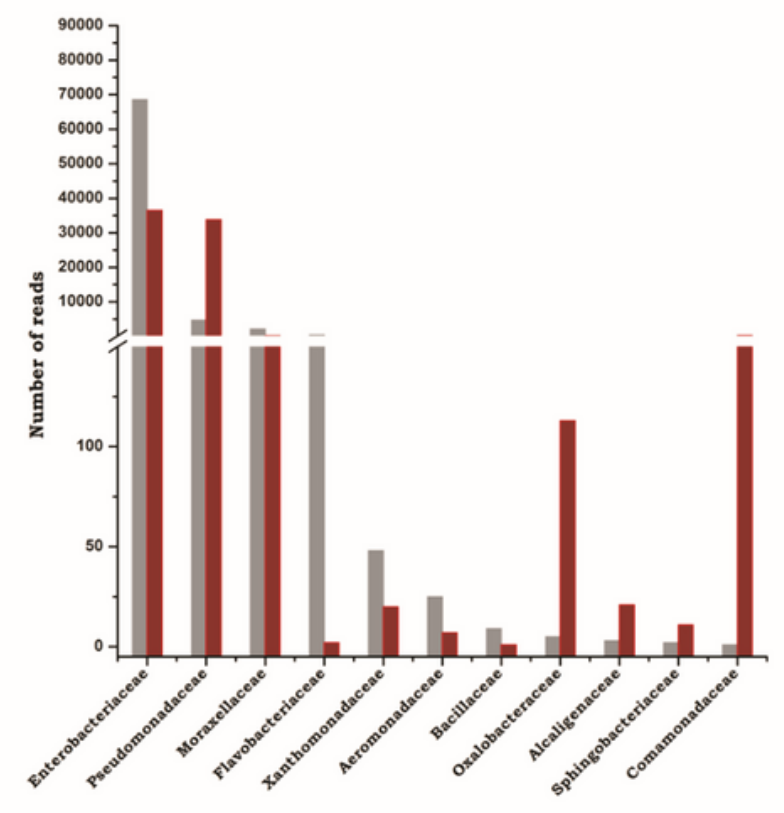

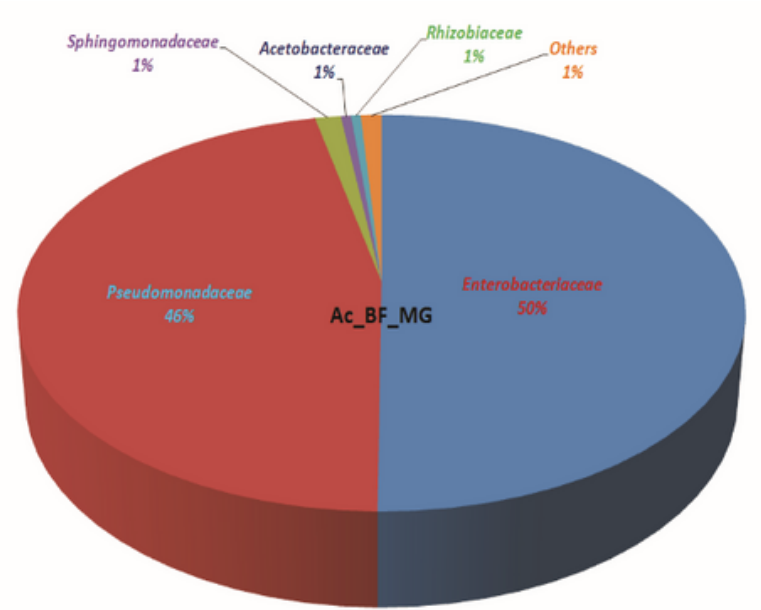

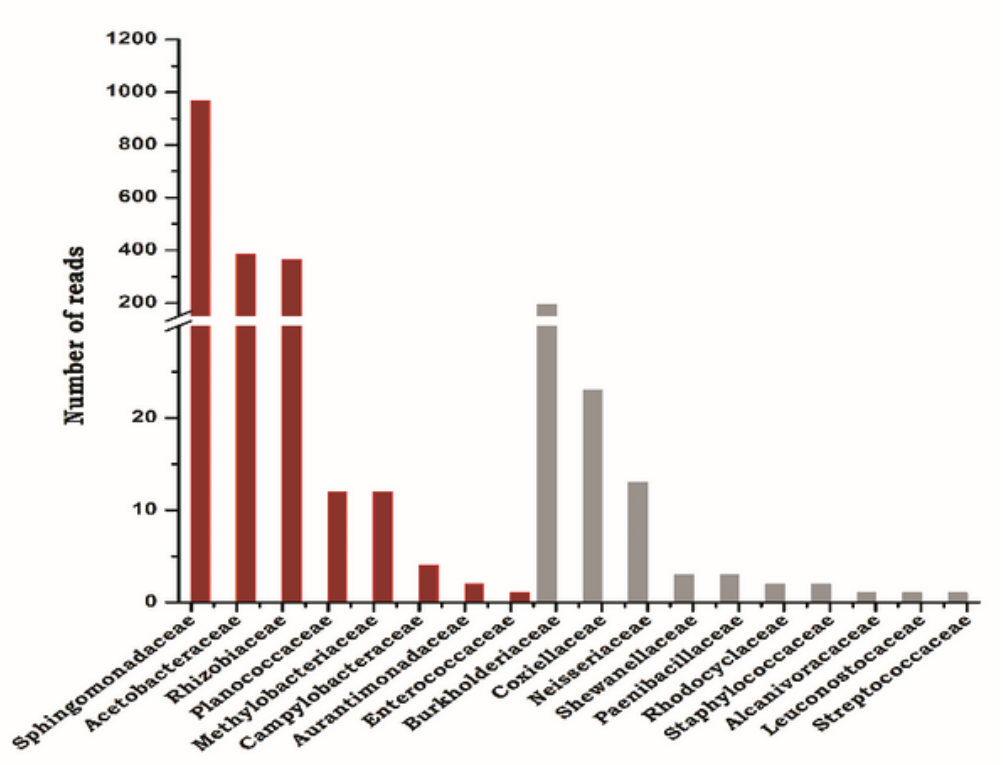

(c)
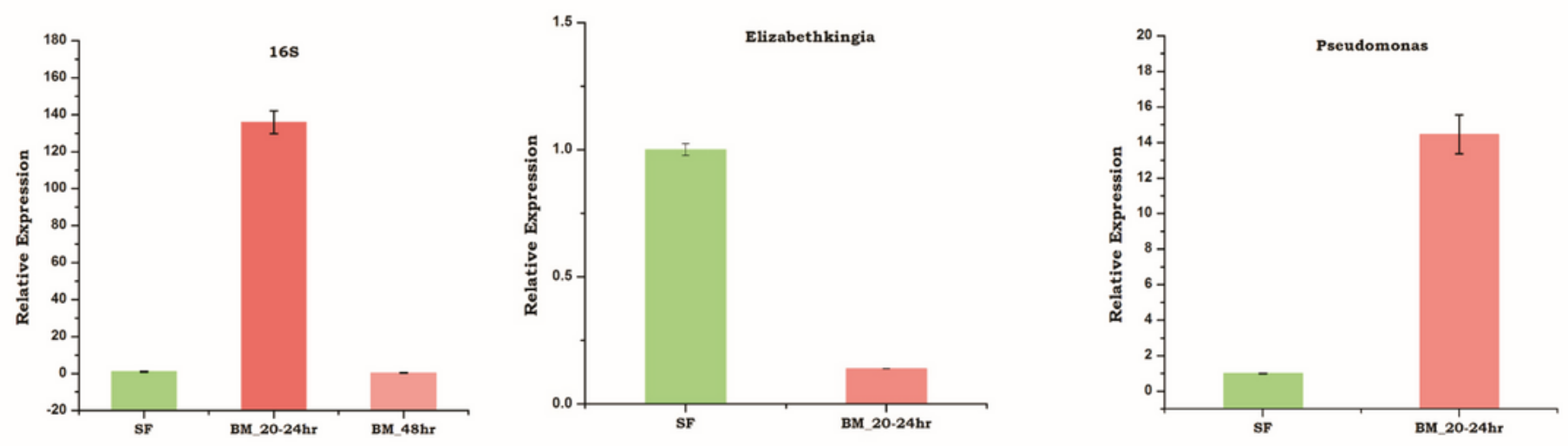

Figure 6

Comparison of gut-metagenomes in the naïve sugar-fed and blood-fed mosquito Anopheles culicifacies: (a) Pie charts representing the major bacterial families under the two feeding status (b) Number of reads based comparative bar graphs showing common and unique families microbes (c) Relative quantitative distribution of microbiota based on 16SrRNA based expression in the midgut of An. culicifacies in 
response to sugar and post blood feeding (20-24hrPBM, 48hr PBM); Relative abundance of Elizabethkingia and Pseudomonas sp. bacteria in sugar-fed and blood-fed (20-24hr PBM) condition.
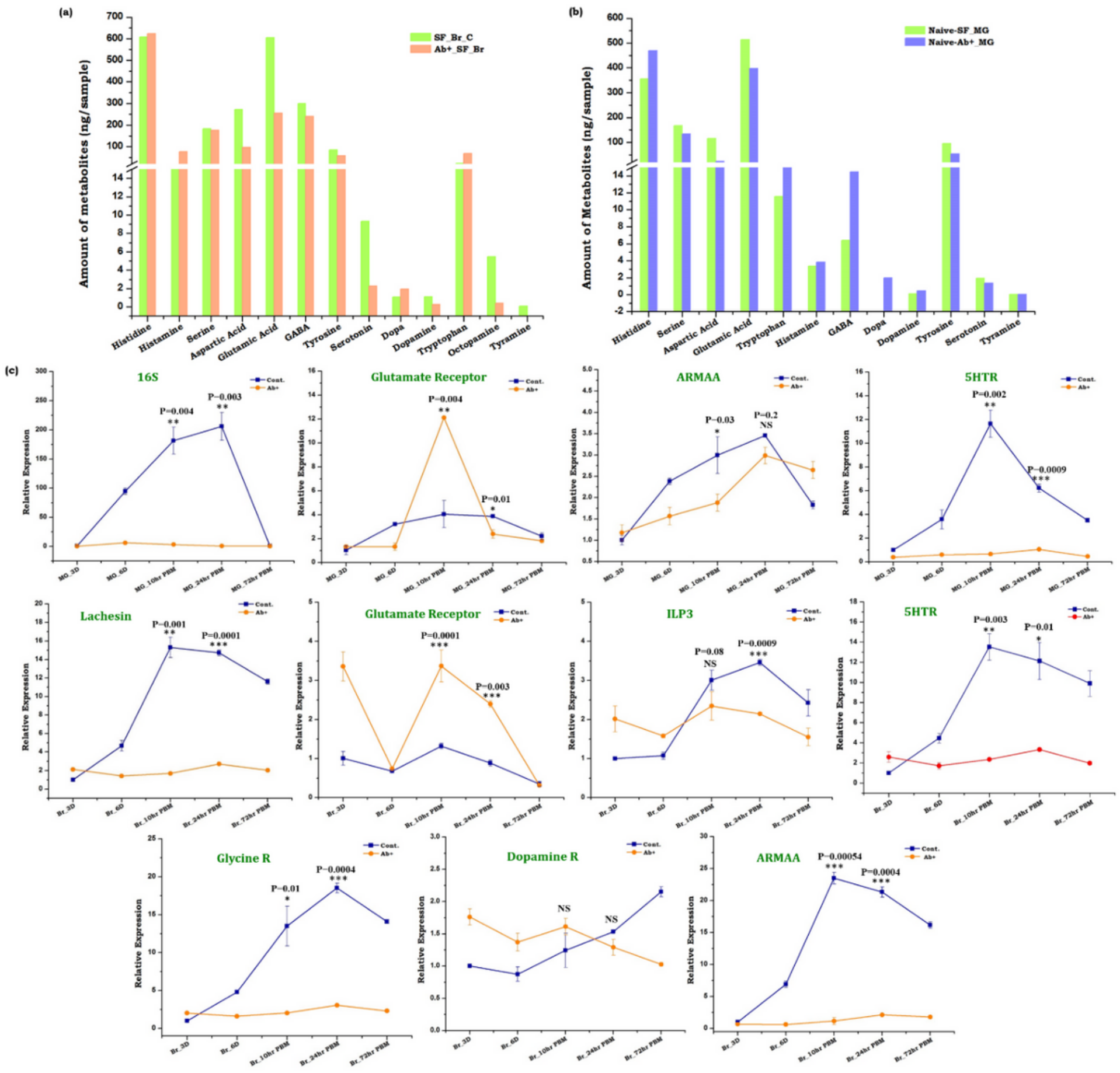

\section{Figure 7}

Establishing Microbiome-Gut-Brain-Axis (MGB) communication in mosquitoes. (a) Absolute quantification of the neurotransmitters (NT) in the brain tissues of naïve sugar-fed and antibiotic-treated mosquitoes ( $n=65, N=2$ ); (b) Quantitative estimation of the neurotransmitters (NT) in the gut tissues of naïve sugar-fed and antibiotic-treated mosquitoes. Statistically significant differences in the amount of metabolites were tested by $p$-values $(p \leq 0.005)$ that are deduced by two-way ANOVA and Tukey's test, ( $n$ 
$=50, \mathrm{~N}=2$ ); (c) Relative expression profiling of the $16 \mathrm{~S}$ gene to show the population of microbial flora and other neuro-transcripts in the gut and brain of naïve and antibiotic-treated mosquitoes undergoing metabolic switch. Statistical significance of differences of the respective genes in control (without antibiotic) and aseptic mosquitoes (antibiotic-treated) were tested by the t-test. ( $n=$ number of mosquitoes from which the respective tissue was dissected and pooled for each independent experiment; $\mathrm{N}=$ number of biological replicates).

(a)

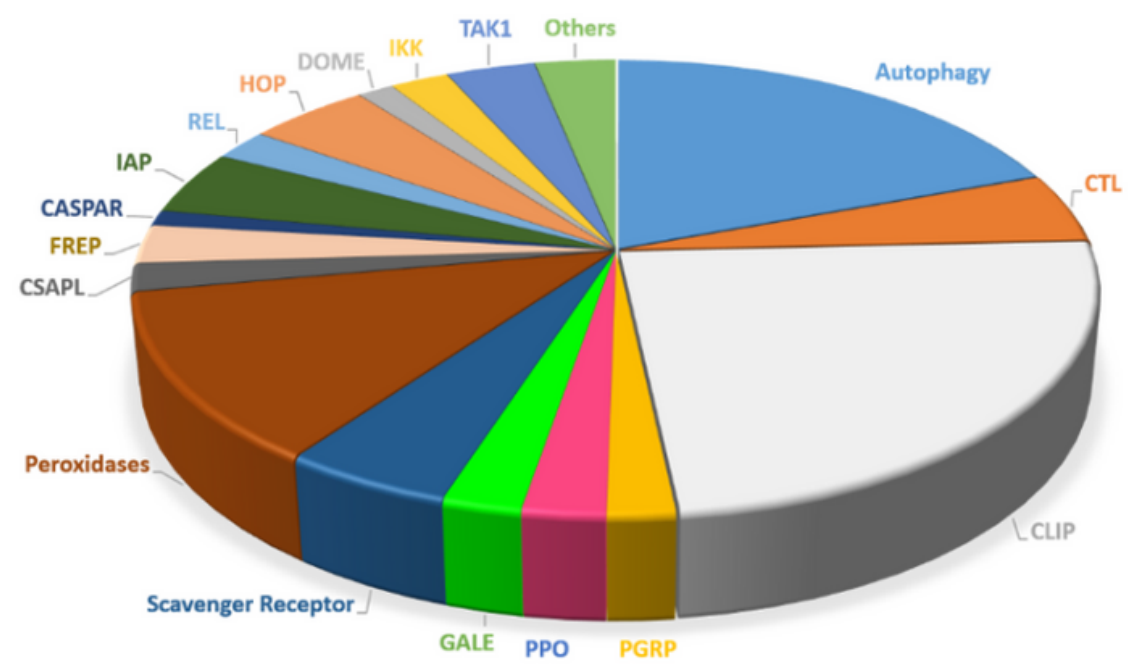

(b)

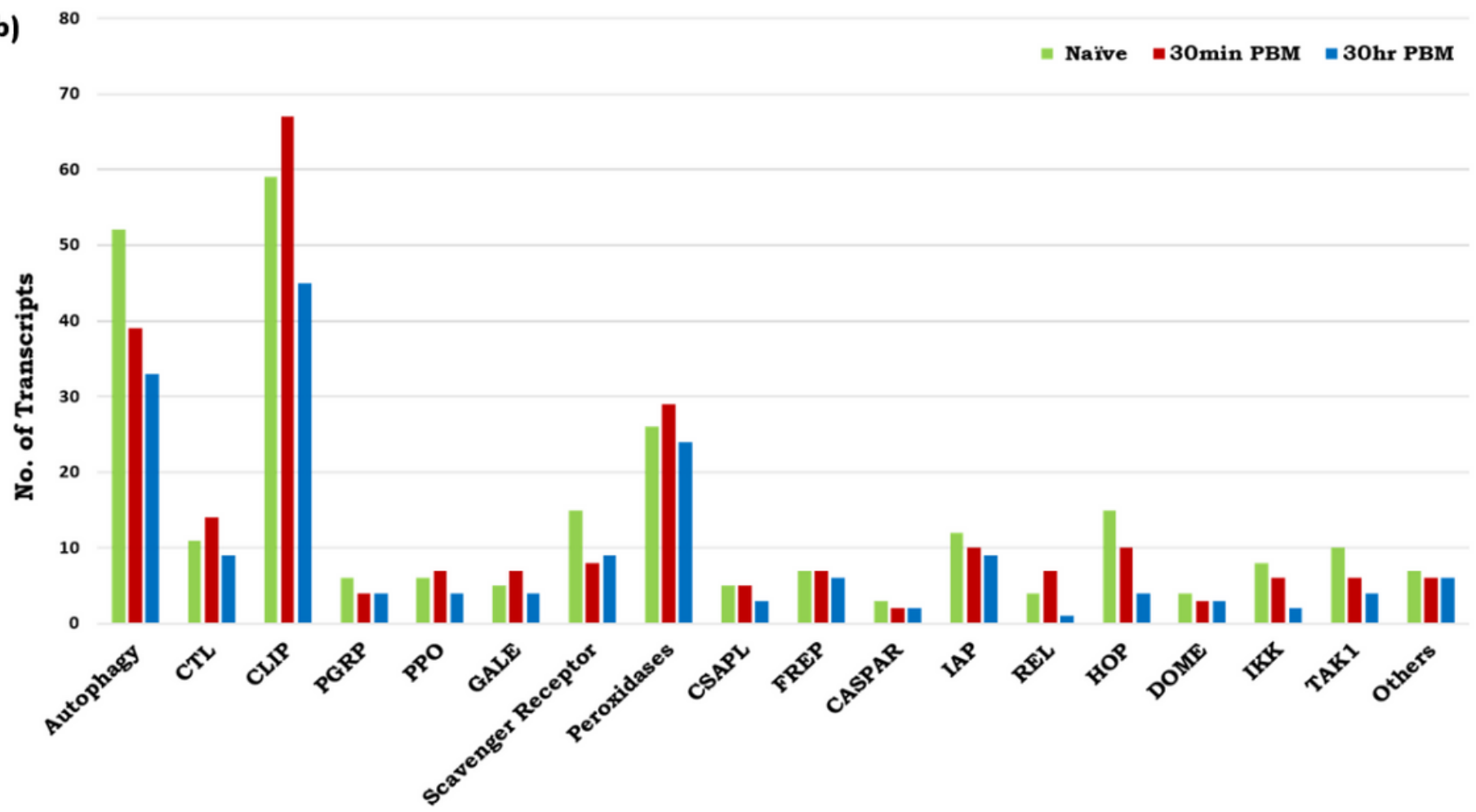

Figure 8

Molecular catalog of brain-specific immune transcripts. (a) Molecular catalog of the different classes of immune genes expressed in brain tissue; (b) Differential expression patterns of the brain immunome as 
determined by the number of sequences that appeared in each RNA-Seq data of naïve and blood-fed mosquito brains.

\section{Supplementary Files}

This is a list of supplementary files associated with this preprint. Click to download.

- graphicalabstract.png

- ACBRAnnotation.xls

- SupportingInformationBrainPaper.pdf 